\title{
Midlatitude Continental Convective Clouds Experiment (MC3E)
}
MP Jensen
AY Hou
WA Petersen
$P$ Kollias
AD Del Genio
B. Orr
SE Giangrande
SA Rutledge
A Heymsfield
MR Schwaller
G Heymsfield
E Zipser

April 2010 


\section{DISCLAIMER}

This report was prepared as an account of work sponsored by the U.S. Government. Neither the United States nor any agency thereof, nor any of their employees, makes any warranty, express or implied, or assumes any legal liability or responsibility for the accuracy, completeness, or usefulness of any information, apparatus, product, or process disclosed, or represents that its use would not infringe privately owned rights. Reference herein to any specific commercial product, process, or service by trade name, trademark, manufacturer, or otherwise, does not necessarily constitute or imply its endorsement, recommendation, or favoring by the U.S. Government or any agency thereof. The views and opinions of authors expressed herein do not necessarily state or reflect those of the U.S. Government or any agency thereof. 


\section{Midlatitude Continental Convective Clouds Experiment (MC3E)}

MP Jensen, Brookhaven National Laboratory

WA Petersen, NASA Marshall Space Flight Center

AD Del Genio, NASA Goddard Institute of Space Studies

SE Giangrande, McGill University

A Heymsfield, NCAR

G Heymsfield, NASA Goddard Space Flight Center

AY Hou, NASA Goddard Space Flight Center

P Kollias, McGill University

B Orr, Argonne National Laboratory

SA Rutledge, Colorado State University

MR Schwaller, NASA Goddard Space Flight Center

E Zipser, University of Utah

April 2010

Work supported by the U.S. Department of Energy,

Office of Science, Office of Biological and Environmental Research 


\section{Summary}

Convective processes play a critical role in the Earth's energy balance through the redistribution of heat and moisture in the atmosphere and subsequent impacts on the hydrologic cycle. Global observation and accurate representation of these processes in numerical models is vital to improving our current understanding and future simulations of Earth's climate system. Despite improvements in computing power, current operational weather and global climate models are unable to resolve the natural temporal and spatial scales that are associated with convective and stratiform precipitation processes; therefore, they must turn to parameterization schemes to represent these processes. In turn, the physical basis for these parameterization schemes needs to be evaluated for general application under a variety of atmospheric conditions. Analogously, space-based remote sensing algorithms designed to retrieve related cloud and precipitation information for use in hydrological, climate, and numerical weather prediction applications often rely on physical "parameterizations" that reliably translate indirectly related instrument measurements to the physical quantity of interest (e.g., precipitation rate). Importantly, both spaceborne retrieval algorithms and model convective parameterization schemes traditionally rely on field campaign data sets as a basis for evaluating and improving the physics of their respective approaches.

The Midlatitude Continental Convective Clouds Experiment (MC3E) will take place in central Oklahoma during the April-May 2011 period. The experiment is a collaborative effort between the U.S. Department of Energy (DOE) Atmospheric Radiation Measurement (ARM) Climate Research Facility and the National Aeronautics and Space Administration's (NASA) Global Precipitation Measurement (GPM) mission Ground Validation (GV) program. The field campaign leverages the unprecedented observing infrastructure currently available in the central United States, combined with an extensive sounding array, remote sensing and in situ aircraft observations, NASA GPM ground validation remote sensors, and new ARM instrumentation purchased with American Recovery and Reinvestment Act funding. The overarching goal is to provide the most complete characterization of convective cloud systems, precipitation, and the environment that has ever been obtained, providing constraints for model cumulus parameterizations and space-based rainfall retrieval algorithms over land that have never before been available. Several different components of convective cloud and precipitation processes tangible to both the convective parameterization and precipitation retrieval algorithm problem are targeted, such as preconvective environment and convective initiation, updraft/downdraft dynamics, condensate transport and detrainment, precipitation and cloud microphysics, spatial and temporal variability of precipitation, influence on the environment and radiation, and a detailed description of the large-scale forcing.

MC3E will use a new multi-scale observing strategy with the participation of a network of distributed sensors (both passive and active). The objective is to document and monitor in 3D not only precipitation, but also clouds, winds, and moisture in an attempt to provide a holistic view of convective clouds, their environment, and associated feedbacks. A goal is to synergistically measure cloud and precipitation characteristics with environmental quantities that are important for remote sensing and retrieval of precipitation characteristics from space, and convective parameterization in large-scale models and cloudresolving model simulations. This will be accomplished through the deployment of several different elements that complement the existing (and soon to become available) ARM facilities: a radiosonde network, NASA scanning multi-parameter radar systems at three different frequencies $(\mathrm{Ka} / \mathrm{Ku} / \mathrm{S})$, NASA high-altitude remote sensing and in situ aircraft, wind profilers, and a dense network of surface 
disdrometers. In addition to these special MC3E instruments, there will be important new instrumentation at the ARM site including: three networked scanning X-band radar systems, four wind profilers, a C-band scanning radar, a dual-wavelength $(\mathrm{Ka} / \mathrm{W})$ scanning cloud radar, a Doppler lidar, and upgraded vertically pointing millimeter cloud radar (MMCR) and micropulse lidar (MPL).

Finally, to fully describe the properties of precipitating cloud systems, coordinated in situ and remote sensing airborne observations are necessary. The University of North Dakota (UND) Citation will provide in situ observations of precipitation-sized particles, ice freezing nuclei, and aerosol concentrations. It is noted from the outset that the Citation will not be able to penetrate the deepest cores of convection associated with spring-time storms in Oklahoma, and thus, the flight plans emphasize sampling in weaker embedded convection and broad stratiform precipitation. As a complement to the UND Citation's in situ observations, the NASA ER-2 provides a high-altitude satellite simulator platform that will enable remote sensing observations with a $\mathrm{Ka} / \mathrm{Ku}$ band radar and passive microwave radiometers.

With these unprecedented observing capabilities comes a greater responsibility to develop synthesis data products suitable for model studies and evaluation and satellite retrieval algorithm development. Thus, special emphasis is given to the growth of a systematic dialogue with the cloud-and large-scale modelers, algorithm developers, and ground-validation scientists for the creation of such 3D data products. Data products that will be especially relevant for MC3E studies include: model forcing data set derived from the radiosonde array, precipitation microphysics from multi-wavelength polarimetric radar and disdrometer observations, 2D and 3D wind retrievals from multi-Doppler radar observations, cloud hydrometeor classification from radar spectra and polarimetric measurements, and cloud and surface precipitation maps derived from radar and surface network observations.

The ARM Climate Research Facility and NASA Precipitation Measurement Missions have been gathering long-term observations of clouds and precipitation for many years. MC3E will offer the opportunity to improve our understanding of the physics of precipitating cloud systems in the Central U.S. towards the goal of improving the modeling of these systems and the measurement of their associated rainfall from space. Furthermore, it is expected that lessons learned from this campaign will foster improvements in long-term remote sensing of precipitating cloud systems for both ARM and NASA GPM for many years to come. 


\section{Contacts}

Del Genio, Anthony Giangrande, Scott Heymsfield, Andrew Heymsfield, Gerald Hou, Arthur Jensen, Michael Kollias, Pavlos Orr, Brad Petersen, Walter Rutledge, Steven Schwaller, Matthew Zipser, Edward

NASA GISS
McGill University
NCAR
NASA GSFC
NASA GSFC
BNL
McGill University
ANL
NASA MSFC
CSU
NASA GSFC
University of Utah

adelgenio@giss,nasa.gov

scott.giangrande@mail.mcgill.ca

heyms1@ucar.edu

heymsfield@agnes.gsfc.nasa.gov arthur.y.hou@nasa.gov

mjensen@bnl.gov

pavlos.kollias@mcgill.ca

brad.orr@anl.gov

walt.petersen@nasa.gov

rutledge@atmos.colostate.edu mathew.r.schwaller@nasa.gov

ed.zipser@utah.edu 


\section{Acronyms and Abbreviations}

2DVD

AERI

AMPR

APR-2

ARM

ARRA

ARSCL

$\mathrm{BF}$

C-SAPR

CAPE

CASA

$\mathrm{CCN}$

CDP

$\mathrm{CF}$

CFAD

CIN

CoSMIR

C-POL

CRM

CRS

CSM

CVI

D3R

DOE

DMT

DPR

DSD

ECMWF

ENSO

GCM

GISS

GMI

GPM

GV
2D Video Disdrometer

Atmospheric Emitted Radiance Interferometer

Advanced Microwave Precipitation Radiometer

Airborne Second Generation Precipitation Radar

Atmospheric Radiation Measurement Climate Research Facility

American Recovery and Reinvestment Act

Active Remote Sensing of Clouds

Boundary Facility

C-band Dual-Polarization Scanning Radar (C-SAPR)

Convective Available Potential Energy

Collaborative Adaptive Sensing of the Atmosphere

Cloud Condensation Nuclei

Cloud Droplet Probe

Central Facility

Contoured Frequency with Altitude Diagram

Convective Inhibition

Conical Scanning Millimeter-wave Imaging Radiometer

C-band Polarimetric

Cloud Resolving Model

Cloud Radar System

Climate System Model

Counterflow Virtual Impactor

Deployable Dual-Polarimetric Doppler Scanning Radar

U.S. Department of Energy

Droplet Measurement Technologies

Dual-Frequency Precipitation Radar

Drop-Size Distribution

European Center for Medium-Range Weather Forecasting

E1 Nino Southern Oscillation

Global Climate Model

Goddard Institute of Space Studies

GPM Microwave Imager

Global Precipitation Measurement

Ground Validation 
HCA

HIWRAP

IFN

IP-1

ISU

JJA

LSM

LST

MC3E

MJO

MMCR

MMF

MPL

NASA

NCEP

NCSM

NEXRAD

NOAA

NPOL

NWS

PIP

PMM

PMS

PMW

PSD

RHI

RICE

SACR

SAPR

SCM

SGP

SID

SPEC

TRMM

TWP

TWP-ICE

UND

VAP
Hydrometeor Classification Algorithm

High-Altitude Imaging Wind and Rain Airborne Profiler

Ice Freezing Nuclei

Integrative Project One

Iowa State University

June, July, and August

Land Surface Model

Local Standard Time

Midlatitude Continental Convective Clouds Experiment

Madden-Julian Oscillation

Millimeter Cloud Radar

Multi-scale Modeling Framework

Micropulse Lidar

National Aeronautic and Space Administration

National Center for Environmental Prediction

Climate System Model v1.4

Next-Generation Radar

National Oceanic and Atmospheric Administration

NASA Polarization Radar

National Weather Service

Precipitation Imaging Probe

Precipitation Measurement Mission

Particle Measuring Systems

Passive Microwave

Particle size distributions

Range Height Indicator

Rosemount Icing

Scanning ARM Cloud Radar

Scanning ARM Precipitation Radar

Single-Column Model

Southern Great Plains

Small Ice Detector

Stratton Park Engineering Company

Tropical Rainfall Measuring Mission

Tropical Western Pacific

Tropical Western Pacific-International Cloud Experiment

University of North Dakota

Value-Added Product 
WRF

WSM6

WSR-88D

$\mathrm{X}$-SAPR

$\mathrm{XDC}$
Weather Research and Forecasting

WRF Single-Moment six-class-scheme

Weather Surveillance Radar 88 Doppler

X-band Scanning ARM Precipitation Radar

External Data Center 


\section{Contents}

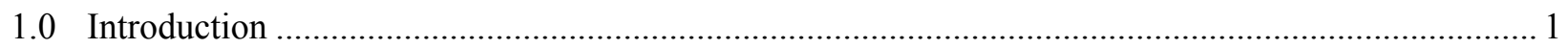

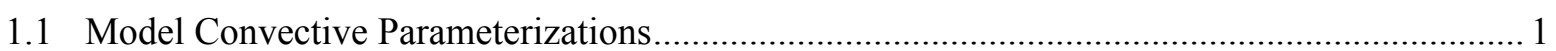

1.2 Improving the Physics of GPM Precipitation Retrieval Algorithms Over Land....................... 5

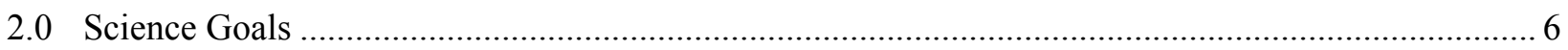

2.1 Advance Understanding of Components of Convective Simulation and Microphysical

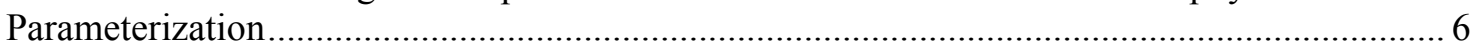

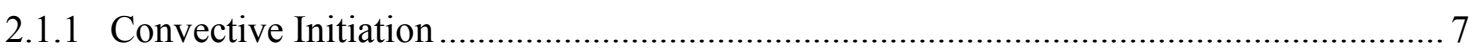

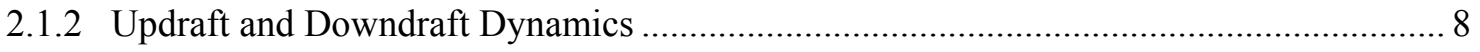

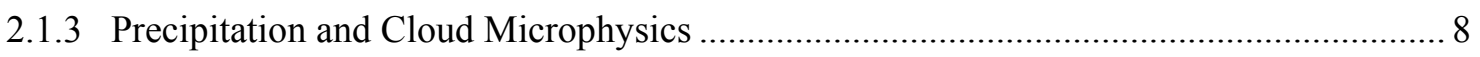

2.2 Improve the Fidelity of Rainfall Estimates Over Land ............................................................ 9

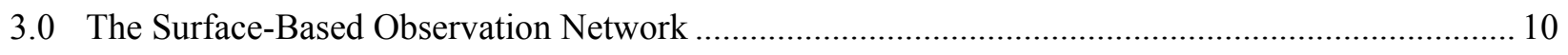

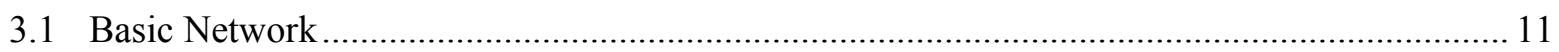

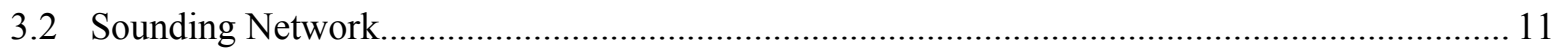

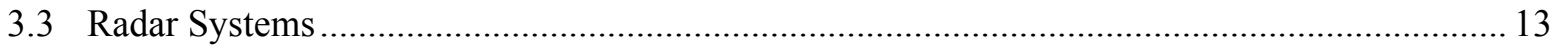

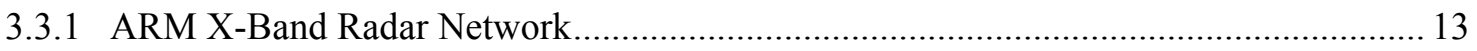

3.3.2 NASA Ka/Ku band Deployable Dual-Polarimetric Doppler Scanning Radar ................. 14

3.3.3 C-band Scanning ARM Precipitation Radar ................................................................ 14

3.3.4 NASA S-Band Transportable Dual-Polarimetric Radar................................................ 15

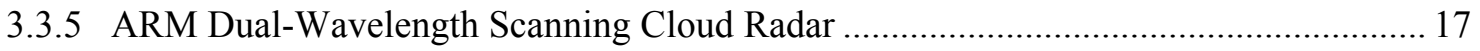

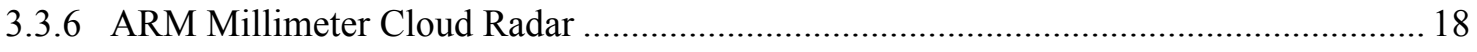

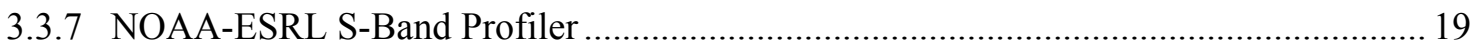

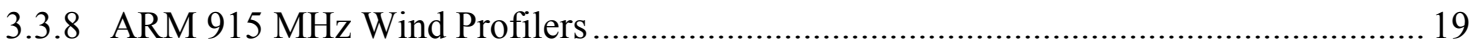

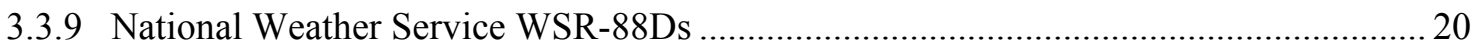

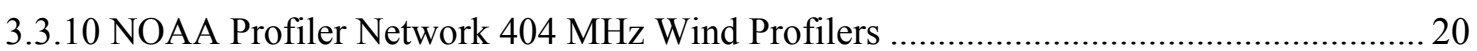

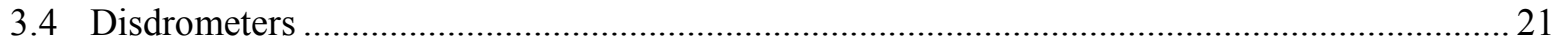

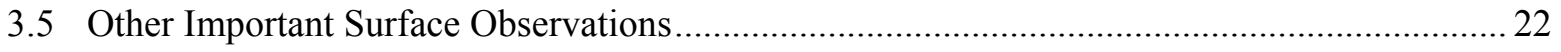

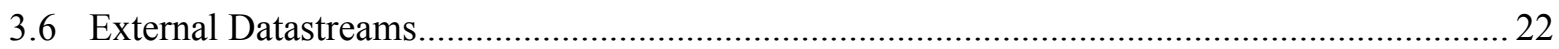

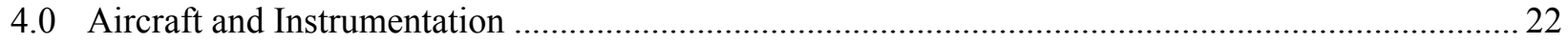

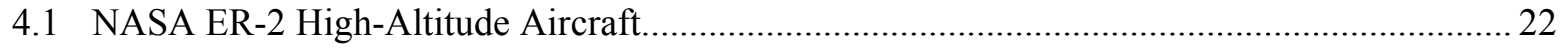

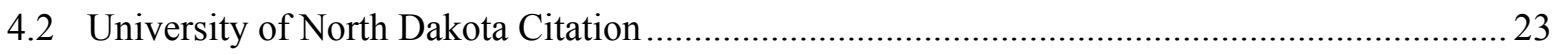

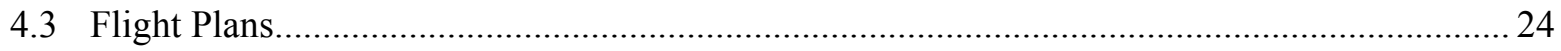

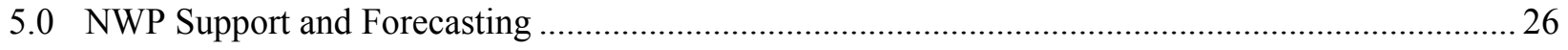

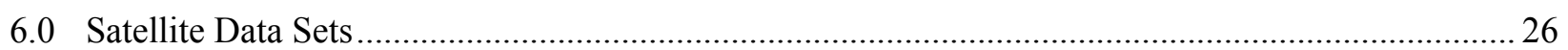

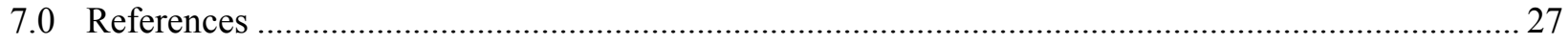




\section{Figures}

1 Left: Mean diurnal cycle of precipitation Right: TWP-ICE monsoon "break" period simulation of scattered mainland convection with WRF model. ..............................................

2 JJA daily precipitation frequencies from TRMM 3B42 satellite observations, NCSM, and CSM

3 WRF hydrometeor water content profiles for deep convective cells during the active monsoon and break periods during TWP-ICE using the WRF single-moment six-class scheme, Thompson, and Purdue Lin microphysics schemes.

4 Map showing the location of the ARM SGP Central Facility, the tentative locations for the X-band Scanning ARM precipitation radars, the C-band scanning ARM precipitation radar, the NASA S-band scanning polarimetric radar the $915 \mathrm{MHz}$ radar wind profilers, the dual-wavelength scanning cloud radar, the S-band wind profiler, and the radiosonde launch sites.

5 Map showing the ARM SGP extended facilities and tentative locations of the MC3E radiosonde launch sites.

6 An example of radar reflectivity and horizontal winds retrieved from the Collaborative and Adaptive Sensing of the Atmosphere Integrated Project One X-band radar array located in southwestern Oklahoma.

7 Nominal NPOL, D3R locations relative to MC3E radar network.

$835 \mathrm{GHz}$ MMCR best-estimate reflectivity from the ARSCL VAP at the Southern Great Plains Central Facility on June 20, 2007.

9 Mean air velocity in $\mathrm{m} / \mathrm{s}$ retrieved from the vertically pointing $915 \mathrm{MHz}$ profiler deployed at Cement, OK for May 16, 2009.

10 Map showing the nominal coverage of WSR-88D radar systems in the vicinity of the ARM SGP facility.

11 Conceptual diagrams of three flight pattern archetypes to be executed during MC3E

\section{Tables}

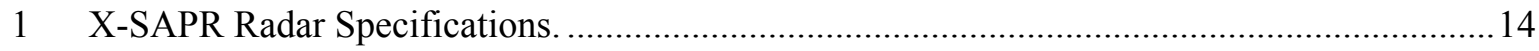

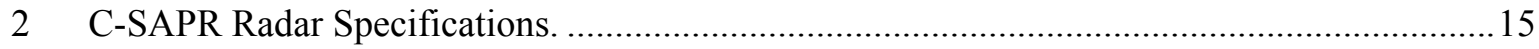

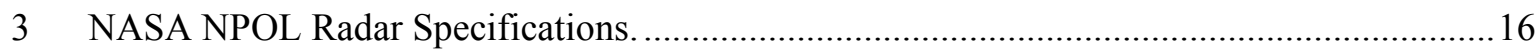

4 Radar characteristics for the ARM dual-wavelength scanning cloud radar............................ 18

5 The National Weather Service WSR-88D radar network in the Oklahoma region. ................20

6 ER-2 Radiometer and Radar complement. ......................................................................23 


\subsection{Introduction}

Convective clouds play a critical role in Earth's climate system. These clouds act as a sink of total water in the atmospheric column through precipitation; contribute to the energy balance through diabatic heating effects; and feedback on the local environment, impacting the subsequent formation of clouds and precipitation.

\subsection{Model Convective Parameterizations}

Dynamical, microphysical, and radiative processes act over a wide range of temporal and spatial scales, making the representation of convective clouds in numerical models one of the most challenging issues faced by the current generation of operational weather and global climate models (Klein and Del Genio 2006). Despite the increase in computational power, the resolutions of large-scale models are unable to resolve convective clouds and precipitation on their natural temporal and spatial scales, and they must turn to parameterization schemes to represent these processes.

Using ARM Facility data sets for evaluating and improving cloud parameterization in global climate models (GCMs) is not straightforward, due to gigantic scale mismatches. Recent modeling efforts include incorporating 2D versions of cloud resolving models (CRMs) directly into each grid box of a GCM to explicitly simulate sub-grid scale clouds and convection (Grabowski and Smolarkiewicz 1999, Grabowski 2001, Khairoutdinov and Randall 2001, Randall et al. 2003). The developers originally dubbed this approach super-parameterization, but have since changed this to Multi-scale Modeling Framework (MMF). The MMF concept considerably reduces the scale mismatch between ARM observations and model spatial and temporal grid scales (Ovtchinnikov et al. 2006) and indicates that the improvement in the parameterization of convective processes in GCMs will have to go through improvement in CRMs. The ability of CRMs to explicitly capture convective dynamics without parameterization is considered to be one of their major strengths. However, convective systems often evolve differently in 2D and 3D CRMs and in lower versus higher resolution 3D GCMs (Bryan et al. 2003). Deep convective case studies observed during MC3E will provide an opportunity to better define which aspects of convective dynamics and evolution are most faithfully simulated by CRMs of different resolutions, thus better informing their use for the development of GCM cumulus parameterizations.

What are some of the outstanding issues related with the parameterization of convective processes in GCMs and CRMs? Clement and Soden (2005) performed a series of model sensitivity experiments to conclude that small changes in the convective precipitation efficiency in a large-scale model can result in changes in the top-of-atmosphere radiative fluxes similar to those observed over the past 20 years. This result, which occurs because a larger fraction of convective condensate that rains out implies less condensate detrained into anvil clouds, underlines the importance of convective parameterization not only for these cloud types and the associated hydrological cycle, but also for the Earth's radiative energy balance. In most GCMs precipitation efficiency is a simple tuning knob, precluding a realistic prediction of convective cloud feedback. In reality, precipitation efficiency depends on the particle size distribution for different hydrometeor classes (liquid, graupel, ice), size-dependent fall speeds, the competition between particle sedimentation and cumulus updraft speed, and the environment into which the precipitation falls (Del Genio et al. 2005). This physics is largely unconstrained by observations and serves as one motivation for MC3E. 
While large-scale models are able to reproduce broad global patterns of precipitation amounts and interseasonal variability, these models generally produce an overabundance of convective precipitation at the expense of stratiform anvil precipitation and show a transition from shallow to deep convection earlier in the day than observations indicate. Dai (2006) compared the precipitation fields from 18 of the latest generation of coupled climate system models against comparative observations. Figure 1 (left) shows a portion of these comparisons. The observations show a general peak in precipitation occurrence in the late afternoon or evening, while the models' peak rainfall occurs near local noon.
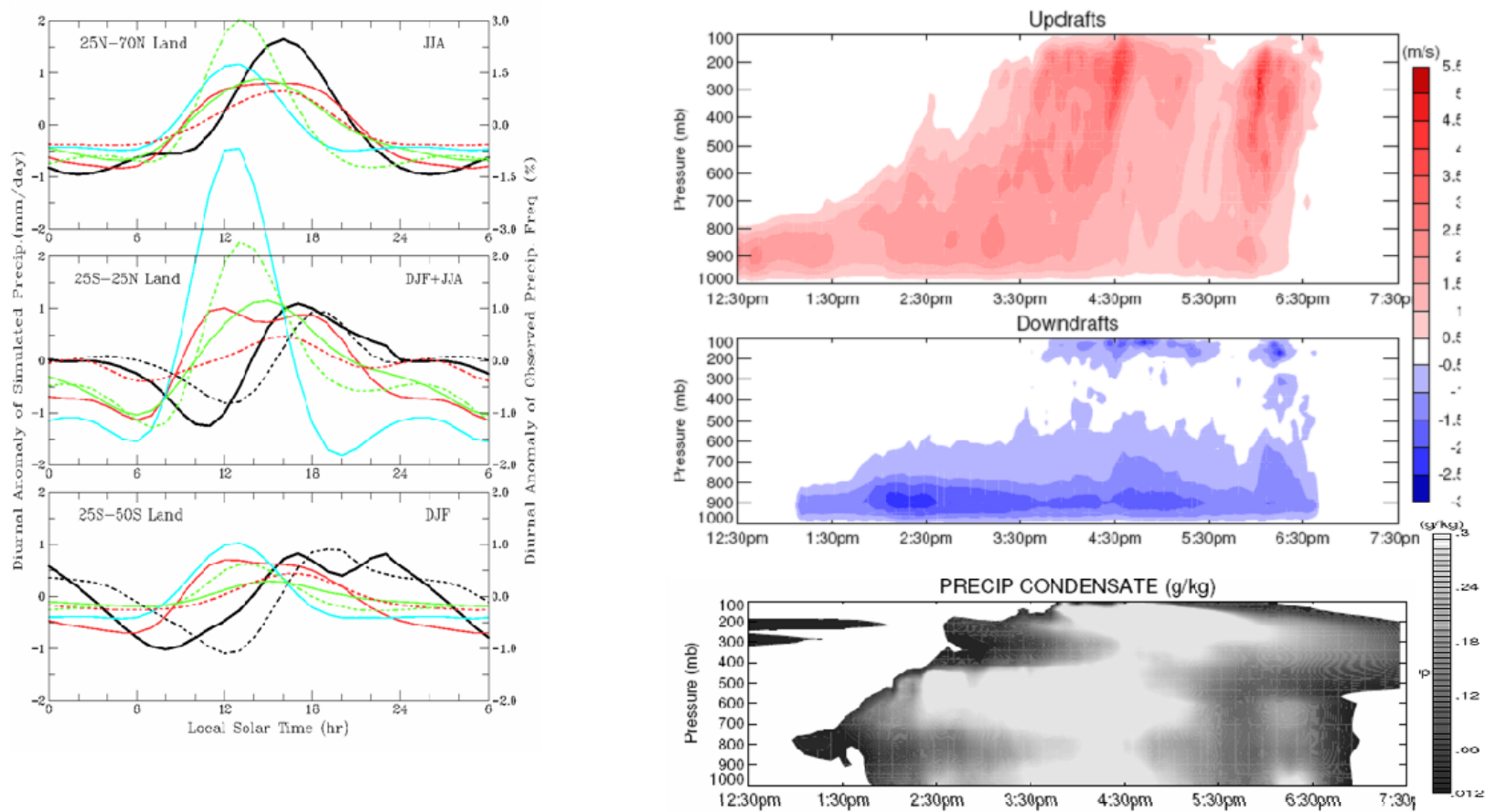

Figure 1. Left: Mean diurnal cycle of precipitation (from Dai 2006, Figure 11). Black solid line is surface observed precipitation from Dai (2001), black dotted line is from the Tropical Rainfall Measuring Mission (TRMM) 3B42 data set, and the colored lines are five different coupled climate models. Right: (from Del Genio and Wu 2010) TWP-ICE monsoon "break" period simulation of scattered mainland convection with WRF model. (a) Updraft velocity $(\mathrm{m} / \mathrm{s}),(\mathrm{b})$ downdraft velocity $(\mathrm{m} / \mathrm{s})$ and precipitation condensate mixing ratio $(\mathrm{g} / \mathrm{kg})$.

In addition to deficiencies in modeling the diurnal cycle, GCM convective parameterizations tend to underestimate the occurrence of the spectrum of convective clouds with the exception of the deepest cloud systems. Work by Derbyshire et al. (2004) and Guichard et al. (2004), comparing results from CRMs and single-column models (SCMs), indicates that the SCMs fail to simulate the links between freetropospheric relative humidity and the related progressive growth in the depth of convective clouds that is observed in CRMs. The SCMs tend to erroneously simulate an instantaneous triggering of deep convective systems as soon as the column becomes unstable. This results in a misrepresentation of the intermediate states of convective cloud growth, which may be precursors to the growth of deep convection leading to incorrect estimation of updraft speeds and convective mass fluxes in deep convective events. These events will in turn impact the microphysical and radiative properties of cumulus anvils (Del Genio et al. 2005). 
Figure 1 (right) illustrates the importance of the transition from shallow convection to deep convection and the important interaction between precipitation, downdrafts, and the triggering of deep convection. This image contains the output from a Weather Research and Forecasting (WRF) model simulation of the development of scattered mainland convection during the Tropical Western Pacific-International Cloud Experiment (TWP-ICE) monsoon break period. As convective downdrafts strengthen, there is a clear transition from shallow, non-precipitating convection to deep, precipitating convection at approximately 2:00 PM LST. Before the formation of convective downdrafts and their associated advancing cold pools, updrafts were limited by entrainment of dry air to the lower troposphere, and there was only weak precipitation formation. Once downdrafts form, cold pools appear in the boundary layer. According to CRMs, this cold pool formation facilitates deeper convection, either by increasing boundary layer eddy size (Kuang and Bretherton 2006, Khairoutdinov and Randall 2006) or by enhancing cloud base updraft speed (Del Genio and $\mathrm{Wu} 2010$ ). Observational constraints on convective vertical motions, which are not routinely available to test such models, are a necessary step in understanding the life cycle of precipitating convective systems.

Dai (2006) also demonstrated that the precipitation frequency is poorly simulated by most coupled GCMs characterized by the overestimation of light precipitation and the underestimation of heavy precipitation. Wu et al. (2007) showed that a deep convection trigger derived from a long-term ARM-validated CRM simulation plays a significant role towards improving the global distribution of precipitation frequency, the Madden-Julian Oscillation (MJO), and the El Nino/Southern Oscillation (ENSO) simulations. Figure 2 displays the frequency distribution of precipitation larger than $1 \mathrm{~mm} \mathrm{day}^{-1}$ over June, July, and August (JJA) of the 10-year (years 80-89) period. The coupled Iowa State University (ISU) GCM (NCSM) with the new trigger clearly rains much less frequently as compared with the National Center for Atmospheric Research Climate System Model (CSM1.4) over the Indian Ocean, the Pacific, and the Atlantic, and is in closer agreement with the TRMM satellite observations over the 6-year (years 19982003 ) period. However, the frequency of heavy precipitation (larger than $20 \mathrm{~mm} /$ day) is higher in NCSM than CSM. NCSM produces more heavy precipitation over North, Central, and South America; the Indian Ocean, and the western Pacific.
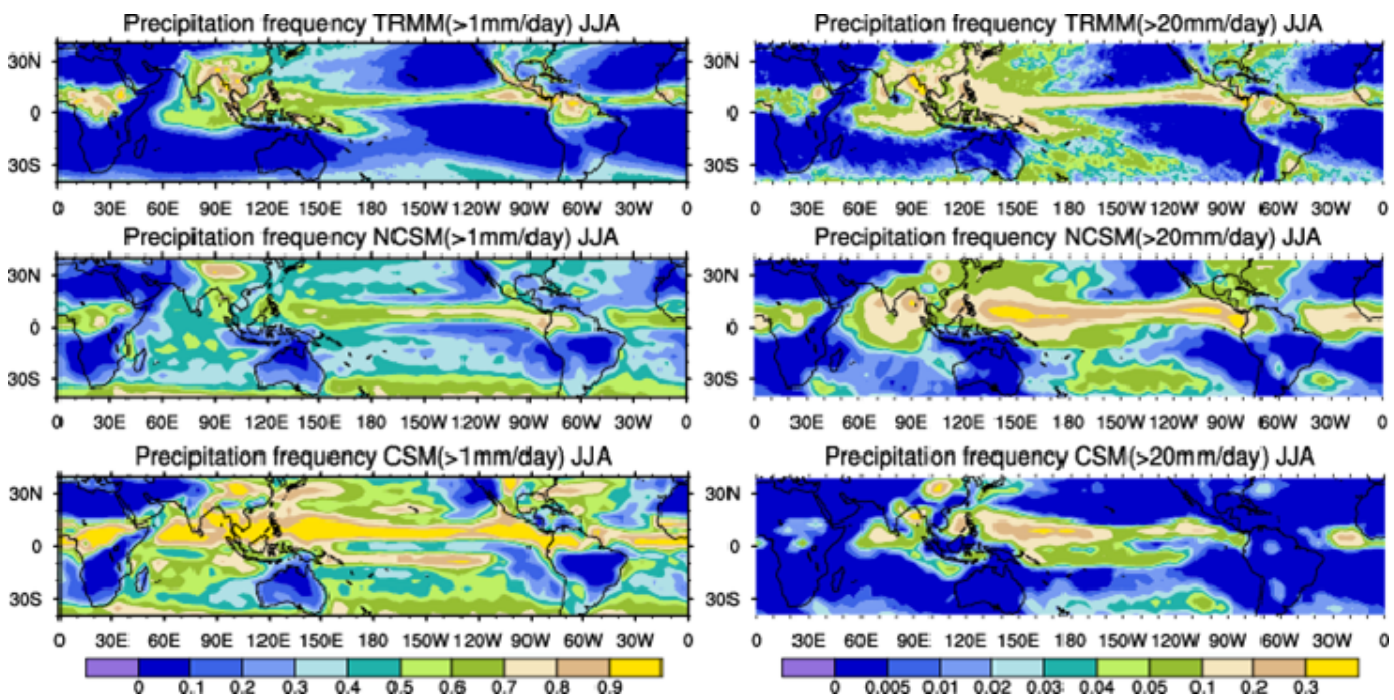

Figure 2. JJA daily precipitation ( $>1 \mathrm{~mm} /$ day, left; $>20 \mathrm{~mm} /$ day, right) frequencies (\%) from TRMM 3B42 satellite observations (1998-2003, top), NCSM (years 80-89, middle), and CSM (years 80-89, bottom). 
The parameterization of cloud and precipitation microphysics in atmospheric models also represents a significant uncertainty in the parameterization of sub-grid scale processes. This is true even of CRMs, since CRM ice-phase and mixed-phase microphysics remain poorly constrained by observations. Wu et al. (2009) investigate the sensitivity of the WRF-modeled hydrometeor water content profiles to the specification of three different microphysics schemes: the WRF single-moment six-class-scheme (WSM6; Hong et al. 2004, Skamarock et al. 2007), the Thompson scheme (Thompson et al. 2004), and the Purdue Lin scheme (Chen and Sun 2002). Each of these schemes includes six hydrometeor classes: water vapor, cloud liquid, rain, cloud ice, snow, and graupel. The Thompson scheme was developed such that it limits the amount of snow and graupel for mid-latitude winter cases. Figure 3 (Figure 6 from Wu et al. 2009) illustrates that for comparisons of the vertical profile of hydrometeor water content during active and break periods of the Australasian monsoon during TWP-ICE, the various microphysical schemes produce significant differences in both the active and break periods. The Thompson scheme produces greater condensate during the break period (particularly in the mid-troposphere), whereas the WRF single moment and Purdue Lin schemes indicate larger active to break differences in the upper troposphere and more graupel during the active period instead.

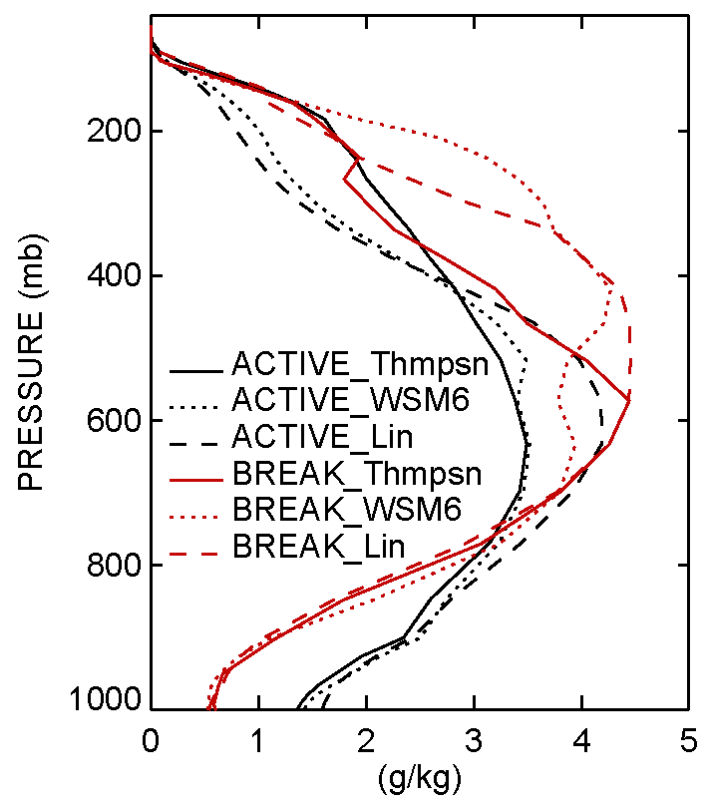

Figure 3. WRF hydrometeor water content profiles for deep convective cells during the active monsoon and break periods during TWP-ICE using the WRF single-moment six-class scheme (WSM6), Thompson, and Purdue Lin microphysics schemes.

These shortcomings of state-of-the-art model GCM and CRM parameterizations are in part the result of the dearth of information until recently on cloud-scale dynamical and microphysical processes within convective systems. Evidence about convective structure along aircraft flight legs has been acquired from numerous field experiments (Lucas et al. 1994, Zipser and Lutz 1994), but with necessary severe sampling limitations and biases, particularly over land (e.g., relatively few flight tracks through strong convective cells). Most satellite data on convective storms has been obtained from passive remote sensors, with the exception of the TRMM and CloudSat radars, which can only observe a single snapshot of each storm and not its full life cycle. Recently, the C-band polarimetric (C-POL) radar deployed at ARM's Darwin Tropical Western Pacific (TWP) site (May and Keenan 2005) has yielded valuable longterm 3D information about reflectivity profiles and hydrometeor types within convective storms. 
However, the environment in which these storms occur is poorly characterized (with the notable exception of the TWP-ICE field campaign), and cloud information is restricted to the soda-straw sampling above Darwin. Polarimetric radar observations of storm lifecycle and 3D reflectivity and hydrometeor type have also been collected during important field campaigns such as the Convective and Precipitation Electrification Experiment in Florida in 1991 (Ramachandran et al. 1996), the Tropical Rainfall Measuring Mission Large-Scale Biosphere Atmosphere (TRMM-LBA) experiment in Brazil in 1999 (Silva Dias et al. 2002), and the North American Monsoon Experiment (NAME) in 2004 (Lang et al.2007). (Note that this represents only a small number of the polarimetric radar datasets that are available). MC3E will build upon the knowledge gained from these prior studies using an unprecedented combination of active 3D sensors in combination with an extensive sounding network. The result will be the most complete characterization of the convection and its environment that has ever been obtained, providing constraints for model cumulus parameterizations that have never before been available.

\subsection{Improving the Physics of GPM Precipitation Retrieval Algorithms Over Land}

To improve the fidelity of rainfall estimates over land at short temporal and spatial scales, the Global Precipitation Measurement mission (GPM) requires development of physically based passive microwave (PMW) precipitation retrieval algorithms anchored by reference dual-frequency precipitation radar (DPR) drop-size distribution (DSD), hydrometeor profile, and rain rate retrievals (Hou et al. 2008). PMW algorithm development/validation over land requires not only an improved understanding of cloud and precipitation microphysics (particularly in the ice and mixed phases), but an improved representation of microphysical processes/properties (at the bulk and particle scales) in relevant cloud and/or empirical models to include improved formulation of the radiative transfer occurring in a variable background of land-surface emissivity. Considering that (1) precipitation estimates made by the GPM satellite constellation will rely heavily on PMW measurements calibrated by combined DPR/PMW retrieval algorithms; (2) there is room for much improvement in current PMW precipitation retrieval algorithms over land ${ }^{1}$; and (3) GPM objectives ascribe considerable importance to making accurate measurements over land where people live, water resources are managed, and flooding occurs; the ability to accurately retrieve precipitation over land using combined DPR/PMW and or PMW-only algorithms, especially those areas not covered by radar and/or rain gauge networks, is critical to the overall success of GPM.

A critical component of the PMW precipitation retrieval algorithms will be the on-orbit measurements provided by the GPM DPR (Hou et al., 2008). A physically based rainfall retrieval algorithm currently exists as a model for implementing single-frequency $(\mathrm{Ku})$ retrievals (via the TRMM satellite, e.g., Iguchi et al. 2009), but new rainfall and attenuation correction algorithm development must be completed to take full advantage of the multi-frequency DPR capabilities. The success of GPM also hinges on the development and validation of DPR precipitation retrievals.

The fundamental role that CRMs can play in the development and testing of both PMW and DPR algorithms is also acknowledged (e.g., Grecu et al. 2004). Via creation of realistic synthetic data sets, CRMs provide a virtual testbed by which to examine difficult-to-observe quantities and perform sensitivity studies of the PMW/DPR retrieval algorithms, including the diagnosis of related quantities

\footnotetext{
${ }^{1}$ Here we distinguish between predominantly empirical algorithms currently in use, and "robust" implies fully developed and validated.
} 
such as latent heating rates. However, it is also well known that CRMs have weaknesses related to the physical representations of cloud microphysics and the manner in which the model environment is constructed to "force" development of simulated cloudiness and precipitation. The construction of empirical data sets derived from coincident air and ground-based sampling of microphysics, combined with appropriately distributed spatial and temporal sampling of key environmental parameters (e.g., model domain tendencies in wind, temperature, humidity etc.), becomes a key input to the development and validation of CRMs, and consequently to the testing of DPR and PMW algorithms.

Put succinctly: GPM GV activities must vigorously address the issue of physically based PMW, DPR, and combined PMW-DPR precipitation retrievals along with validation of CRMs, placing special emphasis on over-land retrievals, and must do so early in the pre GPM-launch phase. By extension, this activity requires (1) the collection of new observational data sets that extend and improve current microphysical descriptions of the 3D distribution and character (e.g., sizes, phases, precipitation rates etc.) of both cloud and precipitation particles; and (2) observational datasets suitable to initialize/force our best CRMs and to provide robust statistical verification of the simulated clouds and precipitation. Arguably, these activities should also culminate in the clear establishment, early-on, of the capability/fidelity/limitation of CRMs to support precipitation retrieval algorithm development. The aforementioned algorithm needs for GPM will be accomplished via the NASA-DOE Midlatitude Convective Clouds Experiment (MC3E).

\subsection{Science Goals}

The MC3E campaign will focus on several outstanding scientific issues critical to convective simulation and microphysical parameterization in CRMs and the spaceborne remote sensing of precipitation. This experiment seeks to use a multi-scale, multi-frequency, multi-platform observational strategy to provide unprecedented detail in characterizing convection and its environment, providing constraints for model cumulus parameterizations and spaceborne measurements of precipitation over land that have never before been available. The key goals are to:

1. advance the understanding of the different components of convective simulation and microphysical parameterization,

2. improve the fidelity of rainfall estimates over land.

\subsection{Advance Understanding of Components of Convective Simulation and Microphysical Parameterization}

The measurement strategy for this field campaign is to provide a well-defined forcing data set for modeling efforts coupled with advanced radar remote sensing available in the ARM Southern Great Plains (SGP) domain at multi-scales and multi-frequencies complemented by additional remote sensing and in situ observations in order to better understand eight different components of convective simulation and microphysical parameterization: (1) pre-convective environment, (2) convective initiation, (3) updraft/downdraft dynamics, (4) condensate transport/detrainment/entrainment, (5) precipitation and cloud microphysics, (6) influence on the environment, (7) influence on radiation, and (8) large-scale forcing. Emphasis will be placed on defining convective initiation, updraft/downdraft dynamics, and the 
precipitation and cloud microphysics. However, the proposed measurements will lead to insights in each of the eight components important for convective parameterization. Specific motivating science questions include the following:

- Given the evolving atmospheric temperature and water vapor profiles, how accurately can the statistics of precipitation at the ground be predicted as functions of $\mathrm{x}, \mathrm{y}$, and $\mathrm{t}$ ?

- How do the properties of the pre-convective boundary layer and free troposphere control the initiation, location, and intensity of deep convection?

- How does the convective cloud system impact the environment, and how do these impacts affect subsequent cloud formation?

- At what threshold of cloud liquid water content does precipitation start developing?

- How do the characteristics of the precipitation vary as a function of the strength of the convection (i.e., updraft strength)?

- What defines the boundary between convective rainfall, stratiform rainfall, and cloud?

- Can we quantify the evaporation of precipitation as it falls?

- What do drop-size distributions look like as a function of measured environmental, cloud microphysics and dynamics, and precipitation properties?

- Can we quantify the differences in cloud radiative impacts and microphysical properties as a function of precipitation?

\subsubsection{Convective Initiation}

The initiation of convective cloud systems is difficult to predict due to highly non-linear formation processes that occur on very short time and spatial scales, coupled with a lack of observations of the relevant thermodynamic and dynamical fields on these scales. Continental convection is strongly coupled to surface and boundary layer processes. To understand the relationships between convective cloud and precipitation properties and the impacts on the atmospheric energy balance, one must first quantify the atmospheric conditions conducive to the formation of these systems. The task requires defining the vertical and horizontal structure of the atmospheric thermodynamic state and its evolution with an emphasis on the structure within the boundary layer. Small-scale variations in temperature and moisture have been shown to be critical for the initiation of convection, particularly in and just above the boundary layer (Crook et al. 1996). The vertical profiles of temperature and humidity are required to determine the convective available potential energy (CAPE), convective inhibition (CIN), and the presence of any lids to deep convection (Browning et al. 2007).

Surface observations from the Oklahoma (McPherson et al. 2007) and Kansas Mesonet, and the ARM extended facilities will provide baseline observations of the humidity and temperature fields. An enhanced radiosonde array (see Section 3.2) with launches every 3-6 hours will provide profiles of the atmospheric thermodynamic state at the boundaries of the domain. Raman lidar and Atmospheric Emitted Radiance Interferometer (AERI) observations will be used to derive vertical profiles of temperature and moisture over the SGP Central Facility, and radar refractivity observations from the new ARM radar systems will be used to derive high-resolution near-surface humidity (Fabry et al. 1997, Fabry 
2004, Stonitsch and Markowski 2005, Roberts et al. 2008, Cheong et al. 2008). Scanning radar observations will further be able to detect cloud and precipitation features to indicate the initiation of convective events along with passive radiometric observations from geostationary satellites.

\subsubsection{Updraft and Downdraft Dynamics}

The dynamics of the updrafts and downdrafts within convective clouds are important in determining the water fluxes within the cloud system and are therefore directly tied to the energetic impacts of the cloud system. Despite the importance, convective dynamics are poorly understood, difficult to measure, and a cause of great uncertainty in convective parameterization. Some cumulus parameterizations still do not include downdrafts, and many calculate only mass flux, in part because of the paucity of observational constraints. Using the available radar networks, several analysis techniques may be employed to retrieve 3D air motions within convective cloud systems (e.g., Armijo 1969, O’Brien 1970, Ray et al. 1975, Ray et al. 1980, Testud and Chong 1983, Yuter and Houze 1995a, Matejka and Bartels 1998, Shapiro and Mewes 1999, Protat and Zawadzki 2000, Richardson et al. 2003). Multi-Doppler techniques using several combinations of scanning radar observations will be possible with validation opportunities available from vertically pointing radar wind profiler systems. The retrievals provide the basis of comparison and verification of cloud-resolving model case studies and may be analyzed to determine storm-averaged velocities, stratiform/convective updraft/downdraft composites, or contoured frequency by altitude diagrams (CFADs; Yuter and Houze 1995b). Of particular interest for parameterization purposes are the relationship of updraft strength to CAPE and lower tropospheric stability, the relative strength of updrafts and downdrafts, and the dependence of downdraft initiation level on environmental relative humidity. The further analysis of several convective systems in relation to the pre-convective environment and convective initiation may offer connections that need to be properly modeled at all scales.

\subsubsection{Precipitation and Cloud Microphysics}

Estimates of the precipitation and cloud microphysics are important for understanding the cloud and storm systems' impacts on the hydrological cycle and the radiative energy balance, and for more detailed remote sensing applications. The multi-frequency radar observations combined with polarization capabilities can be used to quantify cloud and precipitation microphysics, including cloud and precipitation particle size distributions, total water content, and cloud/precipitation particle phase. Relating these quantities to the pre-storm environment (instability of the temperature profile, wind shear, boundary layer relative humidity, etc.) and the life cycle of the storm may offer important clues to the parameterization of convective processes. These quantities are also important for defining the latent and radiative heating of the precipitating cloud systems. Two approaches for estimation of precipitation and cloud microphysics will be addressed:

a. Microbase-type parameterizations (Jensen and Johnson 2006) for the liquid/ice water content and liquid/water particle effective radius will be applied to the 4D radar reflectivity field. Using a combination of radar (scanning and vertically pointing), lidar, microwave radiometer, and radiosonde observations along with previously published power-law relationships for mapping reflectivity observations to cloud microphysical quantities, we will be able to produce estimates of the required fields. NASA in situ aircraft observations and broadband shortwave/longwave radiative closure (through the BroadBand Radiative Heating Project) will be used for validation of these algorithms. 
b. Hydrometeor classification algorithms (HCA; e.g., Zrnic and Ryzhkov 1999, Vivekanandan et al. 1999, Liu and Chandrashekar 2000, Zrnic et al. 2001, Lim et al. 2005, May and Keenan 2005, Park et al. 2008) employ a "fuzzy logic" scheme on polarimetric radar observations to distinguish bulk hydrometeor classes. Scanning radar systems in the region offer polarimetric capabilities that facilitate the application of bulk HCAs. NASA in situ aircraft observations and other surface observations will act as a useful validation of these algorithms. Wu at al. (2009) show a useful application of this type of hydrometeor classification as they investigate the resulting profiles of graupel occurrence for different model microphysical schemes. The study finds that in most cases, models tend to over-predict the amount of graupel compared to radar observations and tend to show rather large differences in graupel production as a function of tropical monsoon phase and not consistent with radar observations.

\subsection{Improve the Fidelity of Rainfall Estimates Over Land}

The field campaign observations will provide both the DOE-ARM and NASA-GPM communities a means to further establish linkages between macrophysical and microphysical characteristics of precipitating clouds and their associated radiative characteristics as sensed by passive and active microwave instruments deployed on the ground and in space.

Specific to GPM and broadly synergistic with DOE-ARM MC3E goals, GPM science objectives for the MC3E field campaign include:

1. Collection of cloud microstructures (cloud water, cloud ice, liquid, mixed and solid precipitation phases), particle sizes and shapes with size distributions, high-resolution melting-layer characteristics, rainfall rates, and aerosol characteristics (e.g., cloud condensation nuclei and ice freezing nuclei concentrations) in a mid-latitude land environment during the varying "regimes" of the boreal spring and summer transition under the TRMM and CloudSat fields of view.

2. Evaluation of the core complement of GPM GV instrumentation (aircraft, radars, profilers, disdrometers, etc.) to specifically include sampling/measurement methodologies and assessment of associated error characteristics as applied to mid-latitude temperate-climate precipitation measurements.

3. Quantification of surface radiative (multi-channel microwave), sensible and latent heat fluxes (including soil moisture) to support coupled land-surface model (LSM)/CRM modeling.

4. Construction of accurate large-scale forcing environments for CRM simulations (i.e., remove the issue of quality forcing data sets as an issue for the accuracy of the CRM).

5. Testing of CRM simulation fidelity via intensive statistical comparisons of simulated to observed cloud properties and latent heating fields (e.g., using radar and ARM SGP sounding array data) in a variety of case types (leveraging seasonal transition in regimes over Oklahoma).

6. Further establishment of CRM space-time integrating capability for quantitative precipitation estimation.

7. Supported by items 1-6, development and refinement of a physically based GPM passive microwave retrieval algorithm for use over land (this objective could also test empirical approaches).

8. Supported by items $1-6$ and use of ground-based (GPM-GV) and airborne (High-Altitude Imaging Wind and Rain Airborne Profiler [HIWRAP] or the Airborne Second Generation Precipitation Radar [APR-2]) $\mathrm{Ku}-\mathrm{Ka}$ band radars with other available radar frequencies (S, X, W, etc.) and CRM simulations, further develop/refine GPM DPR attenuation correction and precipitation retrieval algorithm. 
Collectively, the aforementioned objectives are consistent with the following sampling/data priorities and measurement approaches for GPM field work during MC3E:

1. Coordinated and collocated airborne remote sensing of precipitation using high-altitude simulator instruments flown on the NASA ER-2 (radiometer and $\mathrm{Ka} / \mathrm{Ku}$ band dual-frequency radar suite) stacked with an in situ microphysics aircraft sampling the full range of the precipitation (ice emphasis) particle spectrum (excluding intense storms).

2. High altitude pre- and post-storm radiometer sampling of the land surface radiance/surface backscatter cross-section at DPR/GMI (GPM Microwave Imager) frequencies.

3. High-resolution 4D sampling of hydrometeor characteristics (size, shape, rate, numbers, etc.) including decorrelation of those characteristics over GPM core satellite sub-pixel scales.

4. Collection of sounding network and multi-Doppler data sets that enable forcing and statistical validation of coupled CRM/LSM models.

Of particular interest to GPM will be the 4D behavior of precipitation as it relates to both the physical characteristics of the rain and how those characteristics interact with the measurements to produce error in the estimation of the "true" rain rate (using both spaceborne, aircraft, and ground-based GV measurements). This information has direct bearing on the satellite algorithms through its effect on sampling error, beam filling at pixel scales, and validation of the satellite estimates. The MC3E precipitation network will thus consist of broad-area multi-frequency polarimetric radar measurements of precipitation at $0.5-1 \mathrm{~km}$ scales, combined with a network of "point" measurements (rain gauges and disdrometers) arranged in spatially dense arrays (e.g., 0.5-1 km separations). Collectively, this arrangement will enable multi-instrument evaluation of precipitation variance properties at sub-satellite pixel scales. For example, by analyzing both DSD and coincident rain rate properties at $0.5-1 \mathrm{~km}$ or finer scales with gauge/disdrometer instruments of a priori known error characteristics, it should be possible to understand measurement error characteristics of the precipitation as a function of space and time (e.g., Miriovsky et al. 2004, Habib and Krajewski 2002, Ciach and Krajewski 2006). In turn this information can be "upscaled" to constrain polarimetric radar retrievals that subsequently provide a much broader 3D sampling of precipitation characteristics on horizontal scales smaller than that intrinsic to the sampling scale of the GPM satellite instruments (i.e., O [5 km]). Importantly, these observations can also be explicitly tied to physical process "regimes"-information that can be used a priori in GPM retrieval algorithms to improve the accuracy and precision of rainfall estimates (e.g., Lee and Zawadski 2005).

\subsection{The Surface-Based Observation Network}

The motivation for $\mathrm{MC} 3 \mathrm{E}$ is to advance the understanding of different components of convective parameterization by capitalizing on advanced multi-frequency, multi-scale, active and passive remote sensing, and in situ observations combined with state-of-the-art retrieval algorithms. The MC3E field campaign will take place between approximately April 15, 2011 and June 1, 2011. This late spring transition period emphasizes the climatological maximum in monthly mean precipitation totals and heavy, warm season convective rainfall events in the Oklahoma region as is observed from ARM SGP surface meteorology observations. 


\subsection{Basic Network}

The basic ground-based observing network is shown in Figure 4. This includes the full complement of ARM instrumentation from the Central Facility and extended facilities, the new instrumentation funded for this field campaign, and other relevant external observations.

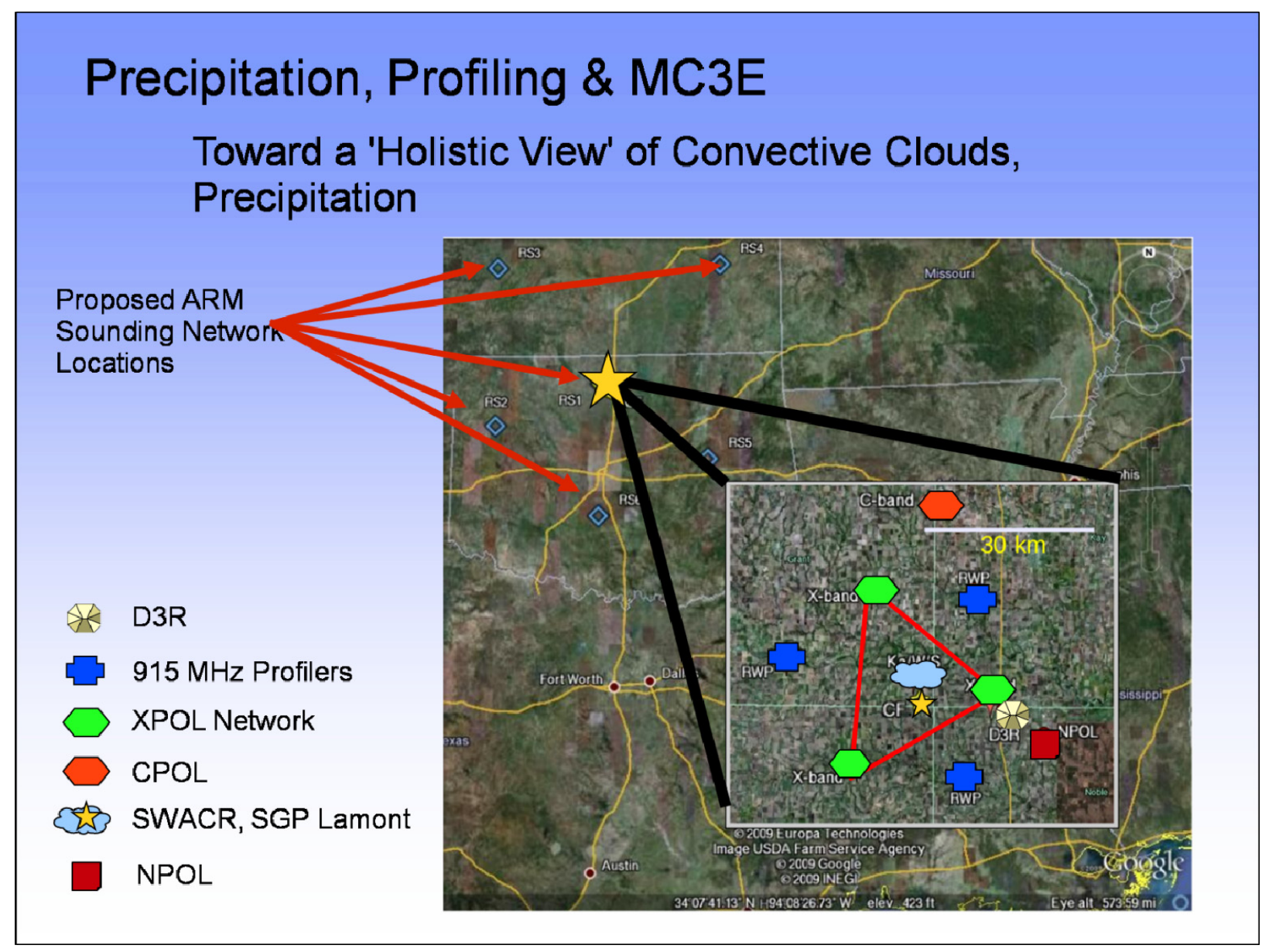

Figure 4. Map showing the location of the ARM SGP Central Facility (CF), the tentative locations for the X-band Scanning ARM precipitation radars (X-band), the C-band scanning ARM precipitation radar, the NASA S-band scanning polarimetric radar (NPOL) [collocated with the NASA $\mathrm{Ka} / \mathrm{Ku}$ scanning radar], the $915 \mathrm{MHz}$ radar wind profilers (RWP), the dualwavelength scanning cloud $\operatorname{radar}(\mathrm{Ka} / \mathrm{W})$, the S-band wind profiler $(\mathrm{S})$, and the radiosonde launch sites (RS). Note that with the exception of the ARM SGP Central Facility all of these siting locations are subject to change.

\subsection{Sounding Network}

ARM Climate Research Facility field campaign funding is primarily requested for a six-site radiosonde array (enhanced CF-1 plus five new sites) at 3-6 hour sampling intervals. The proposed network will cover an area of approximately $300^{2} \mathrm{~km}^{2}$ with five outer sounding launch sites and one central launch location (see Figure 5; Central Facility [CF-1 Lamont], EF-1 Larned, Kansas [38.202 ${ }^{\circ}$ latitude, $-99.316^{\circ}$ longitude]; BF-4 Vici, Oklahoma [36.071, -99.204]; BF-5 Morris, Oklahoma [35.687, -95.856]; and BF- 
6 Purcell, Oklahoma [34.985, -97.522]). Note: All sounding launch locations are subject to final review by the SGP Site Operations team and therefore subject to change). These soundings provide the largescale environmental thermodynamics and offer the opportunity for using the variational constraint method (Zhang and Lin 1997) to compute budgets and large-scale forcing data sets to be used to force singlecolumn climate model studies.

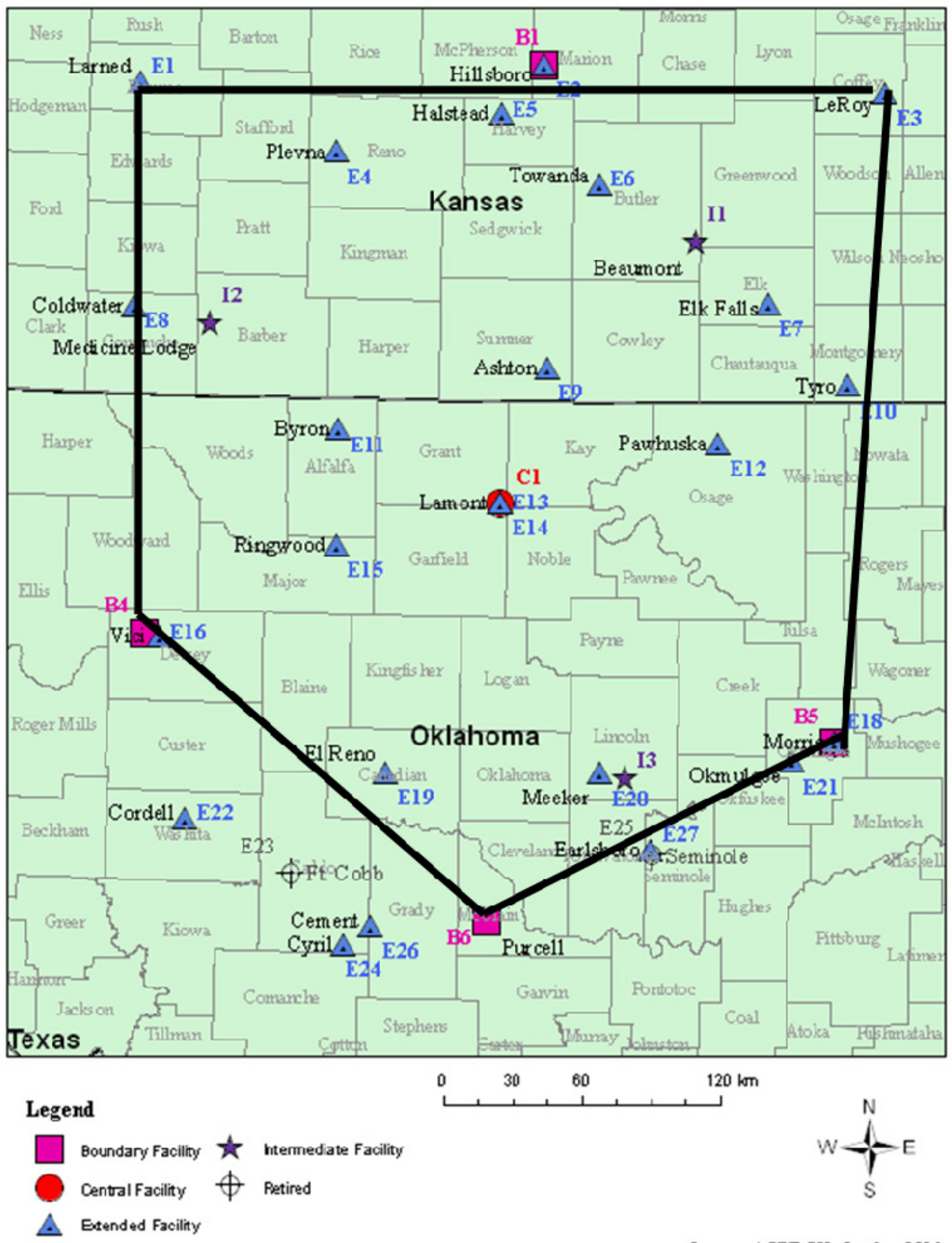

Scuroe: ACRF GIS, Octrber 2005

Figure 5. Map showing the ARM SGP extended facilities (as of 12/11/09) and tentative locations of the $\mathrm{MC} 3 \mathrm{E}$ radiosonde launch sites (E1, E3, B4, B5, B6, C1).

Sounding launch schedules will be based upon the forecast convective conditions. On non-convective days four sondes will be launched per day from each site, while on convective field campaign days, eight 
sondes will be launched per day from each site. Funding levels for the MC3E allow for approximately 1500 sondes over the course of the experiment, which will be partitioned to allow for approximately two weeks of convective field campaign days and four weeks of non-convective launch schedules. The final schedule will be flexible and will depend on the weather conditions and sonde failure rates.

In addition to the ARM sonde measurements, sounding observations from the local National Weather Service (NWS) offices will also prove useful. The quality of the observations (particularly the humidity) can be questionable, but they will still be useful for observing the large-scale structure in atmospheric thermodynamics. Data from the NWS operational soundings are archived by the ARM External Data Center (XDC) for offices in Oklahoma (Oklahoma City, Norman) and Kansas (Topeka, Dodge City).

\subsection{Radar Systems}

\subsubsection{ARM X-Band Radar Network (X-SAPR)}

Through funds from the American Recovery and Reinvestment Act (ARRA), the ARM Climate Research Facility has purchased three X-band (9.6 GHz) Scanning ARM Precipitation Radar (X-SAPR) systems that will be deployed in a triangle with a side of approximately $20 \mathrm{~km}$ centered on the SGP CF (see Figure 4 and Figure 7). The characteristics of these radar systems are summarized in Table 1. The X-SAPR radars will be dual-polarization Doppler radars mounted on a scanning pedestal. The three SGP X-SAPR systems will be deployed in a synergistic sampling mode in order to provide optimal observations of the structure and kinematics of precipitating cloud systems. Most important for the goals of $\mathrm{MC} 3 \mathrm{E}$ is the ability to use multiple Doppler techniques (e.g., see references in Section 2.1.2) for the retrieval of the $3 \mathrm{D}$ wind components within the system; particularly important for our goals is the retrieval of vertical velocity. Figure 6 shows an example of the use of multi-Doppler techniques for the retrieval of horizontal winds from a network of scanning X-band radar systems.

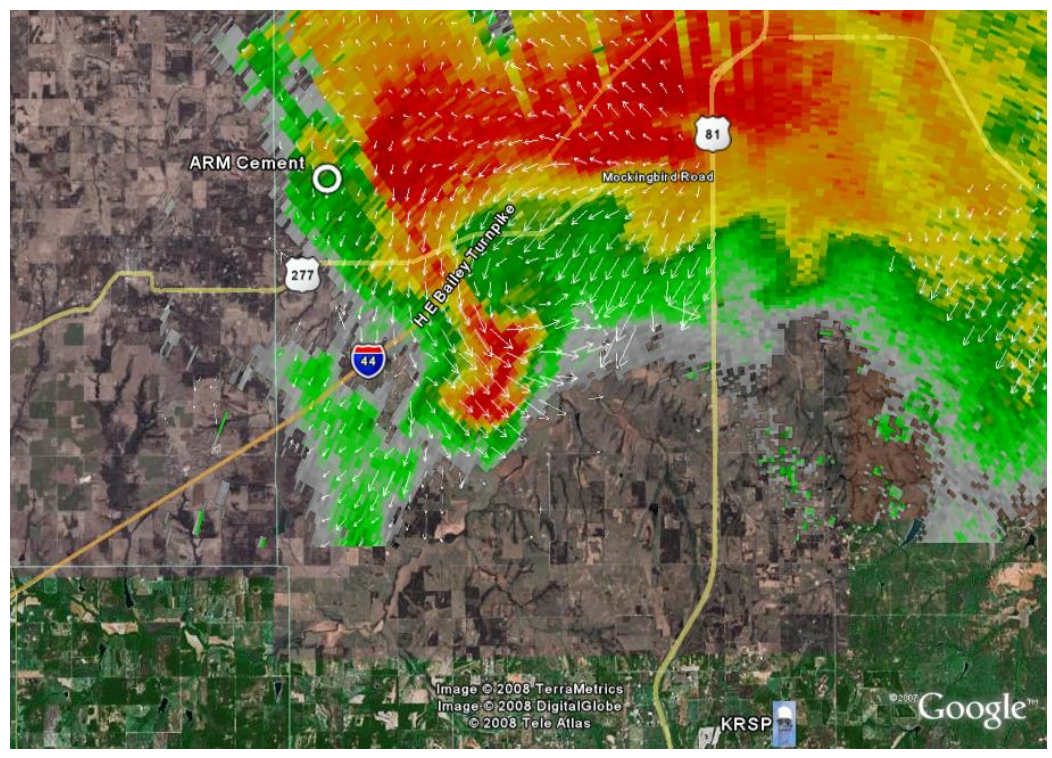

Figure 6. An example (June 14, 2008) of radar reflectivity and horizontal winds retrieved from the Collaborative and Adaptive Sensing of the Atmosphere (CASA) Integrated Project One (IP-1) X-band radar array located in southwestern Oklahoma. 
Table 1. X-SAPR Radar Specifications.

\begin{tabular}{|l|l|}
\hline Component & Specification (nominal requirement) \\
\hline Frequency & $9500+/-30 \mathrm{MHz}$ \\
\hline Polarization & Dual polarization, Simultaneous $\mathrm{H}, \mathrm{V}$ \\
\hline Receiver & Viasala Sigmet RVP900 \\
\hline Variables & $\mathrm{Z}, \mathrm{Z}_{\mathrm{DR}}, \Phi_{\mathrm{DP}}, \mathrm{K}_{\mathrm{DP}}, \rho_{\chi 0}, \rho_{x \xi}$ \\
\hline Transmitter & Magnetron \\
\hline Transmit peak power & $200 \mathrm{~kW}$ \\
\hline Pulse width & $200 \mathrm{~ns}-4.5 \mu \sigma$ \\
\hline PRF & $200 \mathrm{~Hz}-5 \mathrm{kHz}$ \\
\hline Duty cycle & .001 \\
\hline Antenna & $2.4 \mathrm{~meter}$ offset feed \\
\hline Gain & $>45.0 \mathrm{~dB}$ \\
\hline Beam width & $0.9^{\circ}$ \\
\hline
\end{tabular}

\subsubsection{NASA Ka/Ku band Deployable Dual-Polarimetric Doppler Scanning Radar (D3R)}

The NASA Ka-Ku band Deployable Dual-Polarimetric Doppler Scanning Radar (D3R) will provide a ground-based mobile means to bridge observations of cloud and precipitation water in liquid and solid forms using frequencies consistent with the DPR. Plans are to deploy it adjacent to the easternmost of the X-SAPR systems (see Figure 7). The D3R has the following operating characteristics:

- Maximum operating range of $30 \mathrm{~km}$

- Solid-state transmitter, nominal frequencies $13.91 \mathrm{GHz}$ and $35.56 \mathrm{GHz}$

- Variables: Radar reflectivity (Z), differential reflectivity (ZDR), $\Phi_{\mathrm{DP}}$, specific differential phase (KDP), co-polar correlation coefficient $\left(\rho_{\mathrm{co}}\right)$, cross-polar correlation coefficient $\left(\rho_{\mathrm{cx}}\right)$, linear depolarization ratio (LDR), radial velocity (v)

- STSR or alternating (full covariance matrix) pulse schemes

- Design sensitivity of $-10 \mathrm{dBZ}$ at $15 \mathrm{~km}$ (single pulse)

- Scanning, dual-aperture, aligned antennas with beam width $<1^{\circ}$.

\subsubsection{C-band (Dual Polarization) Scanning ARM Precipitation Radar (C-SAPR)}

Through funds from the ARRA, ARM has purchased a C-band $(5.6 \mathrm{GHz})$ dual-polarization scanning radar (C-SAPR) system that will be deployed approximately $25 \mathrm{~km}$ to the north of the SGP CF (see Figure 4 and Figure 7). The characteristics of this radar system are summarized in Table 2. This radar system will serve several purposes during the MC3E campaign, the most important of which is the observation of the life cycle and morphology of convective systems in the vicinity of the SGP CF ( $\sim 100 \mathrm{~km}$ range). This will help to place in situ and smaller-scale observations of the convective systems into the broader context. Radar observations (particularly radial velocity) at C-band are largely 
unaffected or correctable for attenuation in rain within most precipitation regimes including intense convective cells; polarimetric calibration routines and data quality measures also provide added value. The polarimetric capability of this radar system will also allow the estimation of microphysical properties through the application of bulk hydrometeor classification algorithms (see references in Section 2.1.3). NASA in situ aircraft observations and other surface observations will act as a useful validation of these algorithms. Further, this radar system will allow the bulk classification of precipitation type (i.e., convective vs. stratiform), the application of dual-Doppler techniques with other nearby radar systems for the determination of storm dynamical properties, and the quantitative estimation of precipitation amounts.

Table 2. C-SAPR Radar Specifications.

\begin{tabular}{|l|l|}
\hline Component & Specification (nominal requirement) \\
\hline Frequency & $5625+/-25 \mathrm{MHz}$ \\
\hline Polarization & Dual polarization, Simultaneous $\mathrm{H}, \mathrm{V}$ \\
\hline Receiver & Dual-channel $\mathrm{HiQ}$ digital \\
\hline Variables & $\mathrm{Z}, \mathrm{Z}_{\mathrm{DR}}, \Phi_{\mathrm{DP}}, \mathrm{K}_{\mathrm{DP}}, \rho_{\chi \mathrm{o}}, \rho_{\chi \xi}$ \\
\hline Transmitter & Magnetron \\
\hline Transmit peak power & $250 \mathrm{~kW}$ \\
\hline Pulse width & $200 \mathrm{~ns}-2 \mu \mathrm{s}$ \\
\hline PRF & $200 \mathrm{~Hz}-5 \mathrm{kHz}$ \\
\hline Duty cycle & .001 \\
\hline Antenna & $4.27 \mathrm{~meter}$ parabolic reflector \\
\hline Gain & $45.0 \mathrm{~dB}$ \\
\hline Beam width & $0.98^{\circ}$ \\
\hline
\end{tabular}

\subsubsection{NASA S-Band Transportable Dual-Polarimetric Radar (NPOL)}

The NASA NPOL radar will be deployed to the southeast of the SGP CF (see Figure 4 and Figure 7), to provide dual-polarimetric measurements of light to heavy precipitation in liquid, mixed, and ice phase environments - a task well-suited to S-band dual-polarimetric radars. During FY 2010 the radar will undergo an extensive antenna system upgrade (finished August 2010), followed by a testing phase at the Colorado State University CHILL (CSU-CHILL) radar facility, and a complete receiver and transmitter evaluation. It is anticipated that the modified NPOL will provide state of the art research-quality polarimetric data. Characteristics of the radar (as designed; numbers may change on final testing) are presented in Table 3. 
Table 3. NASA NPOL Radar Specifications.

\begin{tabular}{|l|l|}
\hline Component & Specification (nominal requirement) \\
\hline Frequency & $2.7-2.9 \mathrm{GHz}$ \\
\hline Polarization & $\mathrm{H}, \mathrm{V}, \mathrm{STSR}$ \\
\hline Receiver & $\mathrm{RVP} 8$ \\
\hline Variables & $\mathrm{Z}, \mathrm{Z} \Delta \mathrm{P}, \Phi_{\Delta \Pi}, \mathrm{K} \Delta \Pi, \rho_{\chi \mathrm{o}}, \rho_{\chi \xi}, \Lambda \Delta \mathrm{P}, \varsigma \rho$ \\
\hline Transmitter & Magnetron, solid-state pulse modulator \\
\hline Transmit peak power & $850 \mathrm{~kW}(425 \mathrm{~kW} /$ channel in STSR) \\
\hline Pulse width & $0.8-2.0 \mu \sigma$ \\
\hline PRF & $250-2000$ \\
\hline Duty cycle & .0012 \\
\hline Antenna & $8.5 \mathrm{~m}$ prime focal parabolic, no radome \\
\hline Gain & $>44.5 \mathrm{~dB}$ \\
\hline Pointing accuracy & $0.1^{\circ}$ \\
\hline Beam width & $0.9^{\circ}$ \\
\hline Rotation rate & $18^{\circ} / \mathrm{s} \mathrm{maximum}$ \\
\hline First sidelobe & $<-28 \mathrm{~dB}$ \\
\hline X-pol isolation (on axis) & $<-38 \mathrm{~dB}$ \\
\hline Operation & \\
\hline Wind & $<60 \mathrm{mph}$ (sustained) \\
\hline Hail & $<1 \mathrm{~cm}$ \\
\hline & \\
\hline
\end{tabular}

The principal scientific use of NPOL in MC3E will be targeted toward high-quality polarimetric observations of microphysical processes in the vertical column. Use of NPOL in this fashion will satisfy GPM scientific objectives that place a premium on the distributions of particle size, shape, and phase in the vertical. NPOL will be capable of range height indicator (RHI), as well as full, and sector-volumes via plan-position indicator (PPI) scanning. The scanning strategy will be developed to emphasize vertical structure sampling via RHI and narrow sector-volume (e.g., $90^{\circ}$ azimuthal width) data collections. This scanning will be directed to interrogate regions of precipitation being sampled by aircraft and occurring over the CF disdrometer, wind profiler, and cloud-radar arrays. Scanning will be optimized with the remaining $\mathrm{MC} 3 \mathrm{E}$ scanning radar assets to ensure a temporal sampling resolution of $\sim 5$ minutes or less per scan sequence. High-temporal resolution rain-mapping scans (1-3 elevation angles) will also be collected by the NPOL at low levels to facilitate rain and DSD variability studies (decorrelation length, times). Vertically pointing scans will be conducted on a targeted basis in light stratiform precipitation to facilitate calibration of differential reflectivity $\left(Z_{\mathrm{DR}}\right)$. Other modifications to NPOL scanning will be considered as-needed based on science priorities. 


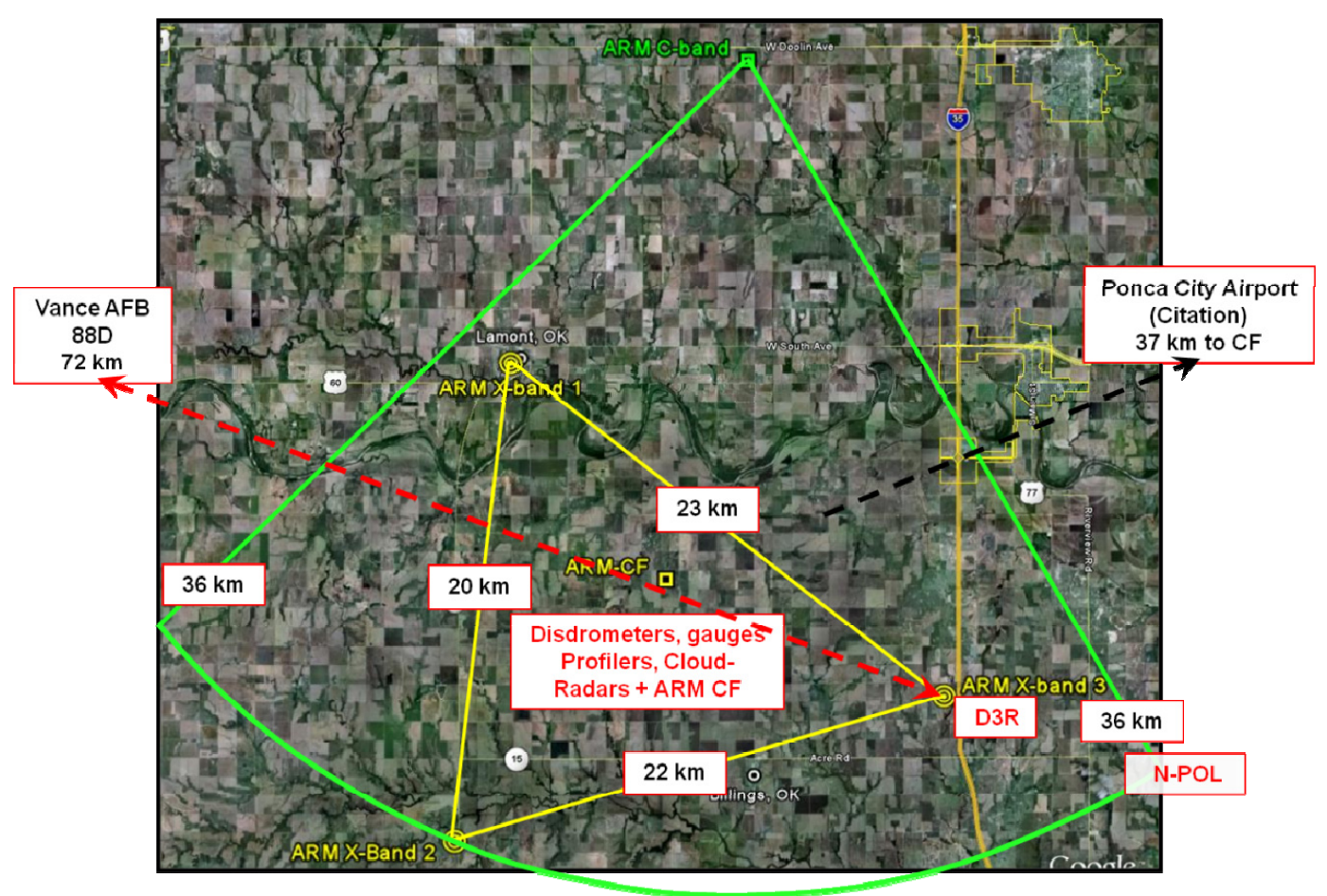

Figure 7. Nominal NPOL, D3R locations relative to MC3E radar network.

\subsubsection{ARM Dual-Wavelength (Ka/W) Scanning Cloud Radar}

Through funds from the ARRA, the ARM Climate Research Facility has purchased a dual-wavelength $\mathrm{Ka} / \mathrm{W}$-band scanning cloud radar/radiometer system (Ka-SACR/W-SACR) that will be deployed at the SGP CF. This dual-frequency cloud radar/radiometer system with Doppler and polarimetric capability will be suitable for simultaneous observations of clouds and precipitation over a 15-20 km range. Its novel design provides rapid scan capability for both the radar and radiometer modes and matching angular resolution (Table 4). The main characteristics of the new, novel cloud/precipitation radar/radiometer system include: (1) dual radar frequency at 94 and $35 \mathrm{GHz}$; (2) radiometric capability build-in in each radar i.e., dual frequency radiometer at 94 and $35 \mathrm{GHz}$ with variable bandwidth for the retrieval of liquid water path; (3) 35-GHz radar antenna beam width of 0.33 degree or less, $94 \mathrm{GHz}$ radar antenna beam width of 0.3 degree or less; (4) matching beam width for the corresponding radiometers; (5) a reliable design with minimum operator intervention and 24/7 operational capability; (6) variable radar range resolution from 30 to $150 \mathrm{~m}$; (7) flexibility to control remotely and change operational characteristics for both the radars and radiometers; and (8) ability to measure reflectivity and Doppler spectra, with polarization desired. The estimated radar sensitivity is $-30 \mathrm{dBZ}$ at $10 \mathrm{~km}$ for typical scanning/sampling conditions. This will enable the detection of clouds in a $20 \mathrm{~km}$ diameter around the ARM Central Facility. 
Table 4. Radar characteristics for the ARM dual-wavelength $(\mathrm{Ka} / \mathrm{W})$ scanning cloud radar.

\begin{tabular}{|l|l|l|}
\hline \multicolumn{1}{|c|}{ Radar Specification } & \multicolumn{1}{c|}{ Ka-SACR } & \multicolumn{1}{c|}{ W-SACR } \\
\hline RF output frequency & $35.29 \mathrm{GHz}$ & $93.93 \mathrm{GHz}$ \\
\hline Peak transmit power from EIKA & $2.2 \mathrm{~kW}$ typical (2 kW min) & $1.7 \mathrm{~kW}$ typical (1.4 kW min) \\
\hline Transmitter duty cycle & $5 \%$ max. & $1 \%$ max. \\
\hline Pulse widths (selectable) & $50-13000 \mathrm{~ns}$ & $50-2000 \mathrm{~ns}$ \\
\hline Transmit polarization & H-pol linear & H-pol linear \\
\hline Receiver polarizations & $\begin{array}{l}\text { Simultaneous Co- and Cross- } \\
\text { polarization linear }\end{array}$ & $\begin{array}{l}\text { Simultaneous Co- and Cross- } \\
\text { polarization linear }\end{array}$ \\
\hline Antenna Diameter & 1.82 m (7") & $\begin{array}{l}.9 \text { m (36") under-illuminated for } \\
\text { beam-matching }\end{array}$ \\
\hline Antenna Beam width & .33 degrees & .29 degrees \\
\hline Cross-polarization isolation & -27 dB typical & -27 dB typical \\
\hline
\end{tabular}

\subsubsection{ARM Millimeter Cloud Radar (MMCR)}

ARM has been operating a vertically pointing $35 \mathrm{GHz}(8.66 \mathrm{~mm}$, Ka-band) millimeter wavelength cloud radar (MMCR; Moran et al. 1998) at the SGP CF since November 1996. The main purpose of this radar is the determination of cloud boundaries in the vertical column, along with radar reflectivity factor (dBZ), mean Doppler velocity, and spectral width. The MMCR operates in six different modes (boundary layer, cirrus, general, precipitation, co-polarization, cross-polarization) optimized for the observation of different cloud types that are often observed in the SGP region. In September 2003 the MMCR processor was upgraded to provide higher reliability and efficiency and to provide the ability to collect full Doppler spectrum measurements.

From the MMCR observations the ARM Facility produces two value-added products (VAP) that will be important for the science goals of MC3E. The Active Remote Sensing of Clouds (ARSCL; Clothiaux et al. 2000) VAP uses a combination of data from the MMCR and MPL, as well as the ceilometer and surface precipitation measurements, to produce best-estimate time-height profiles of hydrometeor locations, radar reflectivities, mean Doppler velocities, and Doppler spectral widths. The MicroARSCL product (Kollias et al. 2007; Luke et al. 2008) gives a summary of characteristics of the Doppler spectrum including information on the number of peaks and the Doppler moment shape parameters. This additional information aids in the extraction of turbulence and microphysical information. Figure 8 shows the bestestimate radar reflectivity from the ARSCL VAP for a precipitating convective system at the SGP CF. The MMCR signal often suffers from severe attenuation during heavy precipitation events and will often experience a decrease in sensitivity following heavy precipitation events due to a wetting of the radome. However, the MMCR generally allows us to define the cloud boundaries and reflectivity profile at much higher sensitivity than longer wavelength radar systems. 


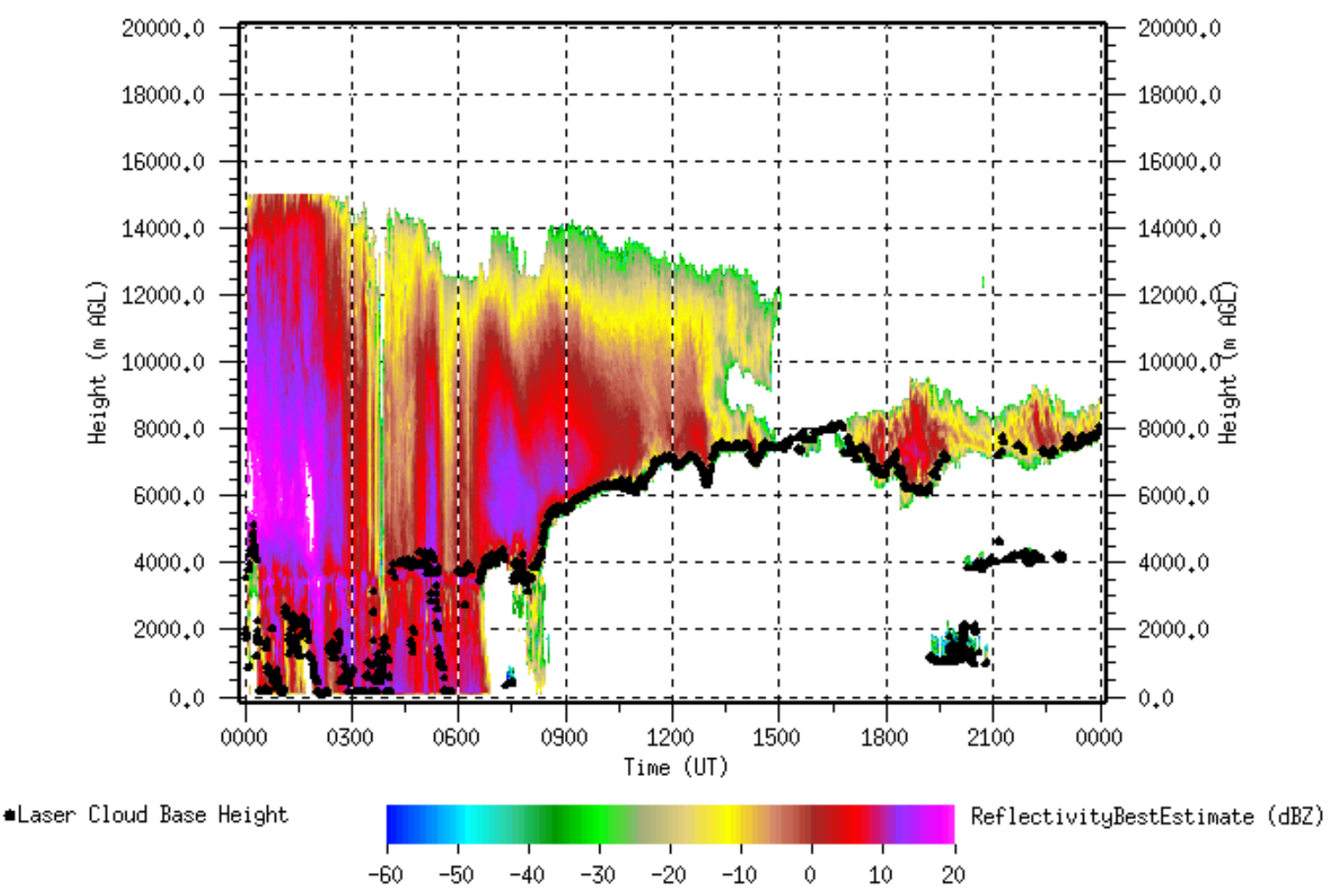

Figure 8. $35 \mathrm{GHz}$ MMCR best-estimate reflectivity from the ARSCL VAP at the Southern Great Plains Central Facility on June 20, 2007.

\subsubsection{NOAA-ESRL S-Band Profiler}

Objectives for deploying an S-band/UHF profiler (Williams et al. 2007) pair include retrieving an unattenuated reflectivity profile through the whole precipitating column and retrieving vertical air motion and raindrop size distribution from near the surface to just below the freezing level. With an operating frequency of 2835-MHz, the S-band vertically pointing profiler will observe un-attenuated reflectivities up to $18 \mathrm{~km}$ above ground with a sensitivity of $-10 \mathrm{dBZ}$ at $10 \mathrm{~km}$. At the operating frequency of $449 \mathrm{MHz}$, the UHF-band vertically pointing profiler (the Doppler beam swinging capability used for wind profiling will be deactivated to devote $100 \%$ time to vertically pointing) will observe the vertical air motion by measuring the backscattered energy from changes in the turbulent refractive index. By subtracting directly observed vertical air motions from the $2835-\mathrm{MHz}$ profiler un-attenuated Doppler velocity reflectivity spectrum, the raindrop size distribution will be retrieved from near the surface to just below the $0^{\circ} \mathrm{C}$ level.

\subsection{8 $\quad$ ARM 915 MHz Wind Profilers}

In 2008, as part of the "Utility of $915 \mathrm{MHz}$ wind profilers for measurements of vertical velocity in convective clouds" field campaign, the configuration of the wind profilers was optimized for the observation of vertical velocities in deep convective cloud systems including decreasing the vertical gate 
spacing to 200 meters with a maximum range of $15 \mathrm{~km}$, increasing the Nyquist velocity to $20.07 \mathrm{~m} / \mathrm{s}$, and decreasing the temporal resolution to 5 seconds. Measurements from these newly configured systems have been used to retrieve the mean vertical velocity and hydrometeor characteristics for several convective systems observed during the campaign (see Figure 9). These vertically pointing observations of mean vertical velocities will act as a validation point for the multi-Doppler retrievals of threedimensional wind vectors from the scanning radar array.

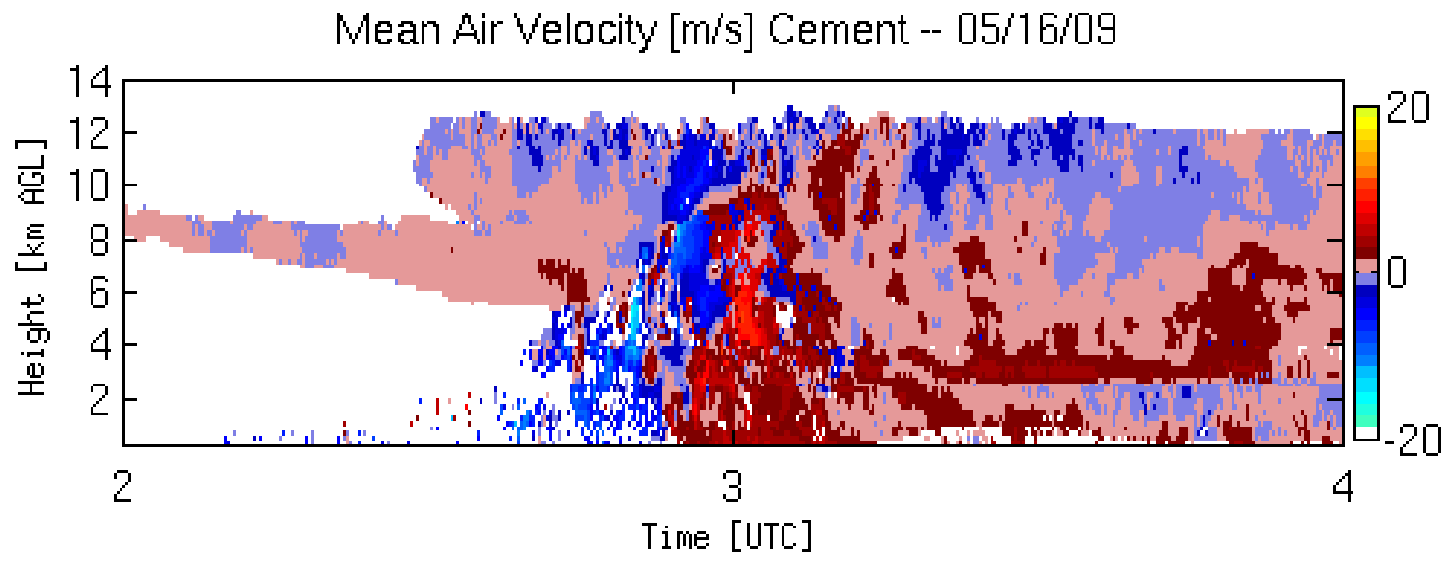

Figure 9. Mean air velocity in $\mathrm{m} / \mathrm{s}$ retrieved from the vertically pointing $915 \mathrm{MHz}$ profiler deployed at Cement, OK for May 16, 2009.

\subsubsection{National Weather Service WSR-88Ds}

The National Weather Service WSR-88D radars in the Oklahoma region provide observations of the large-scale precipitation characteristics over the region. These observations are important for defining the context within which the systems observed by the MC3E radar suite are embedded. By the time of MC3E the WSR-88D radar systems should have gone through an upgrade process that will include polarization capabilities for these operational radar systems. This will provide an additional measurement for determining the class of hydrometeor type in convective storms in the SGP CF region. Table 5 and Figure 10 summarize the WSR-88D locations that will be most useful for this study.

Table 5. The National Weather Service WSR-88D radar network in the Oklahoma region.

\begin{tabular}{|c|c|c|c|}
\hline Location & Station Identifier & Distance from CF & Direction from CF \\
\hline Vance AFB & KVNX & $59.3 \mathrm{~km}$ & West \\
\hline Wichita, KS & KILT & $116.8 \mathrm{~km}$ & North \\
\hline Norman, OK & KOUN & $142.7 \mathrm{~km}$ & South \\
\hline Oklahoma City, OK & KTLX & $143.1 \mathrm{~km}$ & South \\
\hline Tulsa, OK & KINX & $178.4 \mathrm{~km}$ & East \\
\hline
\end{tabular}

\subsubsection{NOAA Profiler Network 404 MHz Wind Profilers}

The National Oceanic and Atmospheric Administration's (NOAA's) profiler network (http://www.profiler.noaa.gov) consists of 35 Doppler radar (404-449 MHz) sites located in 18 different 
states in the Central U.S. and Alaska, providing 6-min profiles of the horizontal wind. Several of these NOAA profiler sites are located in the vicinity of the MC3E sounding array (see Section 3.3) and will provide important boundary conditions for the determination of model forcing data sets. The ARM External Data Center already archives the data from the seven stations surrounding the SGP site [Haviland, KS (37.65, -99.09), Hillsboro, KS (38.31, -97.30), C1-Lamont, OK (36.69, 97.48), B5-Morris, OK $(35.68,95.86)$, Neodesha, KS $(37.38,95.63)$, B6-Purcell, OK $(34.98,-97.52)$, B4-Vici, OK (36.07, 99.22)]. The profiles of the horizontal wind observed by these systems offer an important constraint for the model forcing data set.

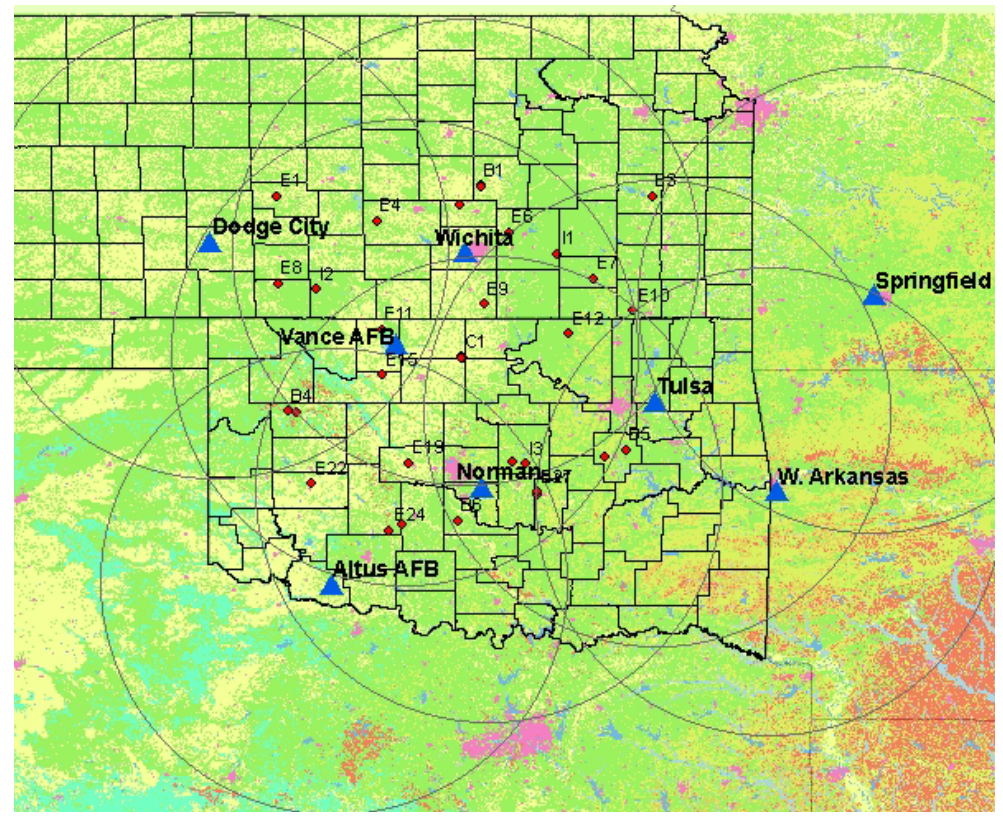

Figure 10. Map showing the nominal coverage of WSR-88D radar systems in the vicinity of the ARM SGP facility.

\subsection{Disdrometers}

Disdrometers will provide a measure of the precipitation size distribution at the surface. These observations offer an important constraint on the retrieval of precipitation properties from remote sensors and help to gain insights into variability in precipitation observations. NASA GPM will deploy more than 20 disdrometers, consisting of five new $3^{\text {rd }}$-generation compact 2D Video Disdrometers (2DVD) and 16 or more Parsivel Disdrometers in a network configuration (final configuration dependent on site logistics) around the SGP CF. The network will be established to resolve/measure variations in rain rate type, intensity, and size distributions (e.g., $\mathrm{D}_{0}$ ) on scales $1-5 \mathrm{~km}$ (order of the GPM footprint) within an area of $\sim 25 \mathrm{~km}^{2}$. The 2DVDs will provide anchor points for assuring overall calibration of the entire array as well as a reference for calibrating the NPOL and D3R radars. The 2DVDs will operate on commercial power and network connections while the Parsivels will be configured to operate autonomously if required. The 2DVDs will provide measurements of particle size and concentration for particles of 0.3$8 \mathrm{~mm}$ in diameter (bin resolution of $0.25 \mathrm{~mm}$ ), axis ratio distribution, and fall-velocity information. The Parsivel network will provide measures of rain DSD, particle phase, and fall-velocity. Particle sizes detected will range from $0.3 \mathrm{~mm}$ to $20 \mathrm{~cm}$, with a geometrically increasing bin size from $0.125 \mathrm{~mm}$ at $0.3 \mathrm{~mm}$ to $1 \mathrm{~mm}$ at $6 \mathrm{~mm}$ drop diameters. 
In addition to the NASA disdrometer array, ARM has a Joss-Waldvogel (JW; Joss and Waldvogel 1969) impact disdrometer deployed at the $\mathrm{CF}$ and will have additional impact disdrometers deployed adjacent to the $915 \mathrm{MHz}$ wind profilers (from NASA GPM), the C-SAPR, and the X-SAPRs.

\subsection{Other Important Surface Observations}

ARM has operated a full suite of cloud, radiation, and atmospheric state observations in the SGP region for a period of nearly 15 years. The continuous operation of most of this instrumentation is an important component towards the completion of the science objectives of MC3E. Of particular importance is the new ARRA instrumentation, including the Doppler Lidar for the retrieval of boundary-layer winds in clear air, the upgraded micropulse lidar for the determination of cloud bases, the upgraded Raman lidar for the retrieval of high time resolution vertical profiles of water vapor, and scanning microwave radiometers for observations of liquid water path and integrated water vapor content. Continuation of the long-term observations at the Central Facility and extended facilities is also an important, especially observations of the surface meteorology ( $\mathrm{T}, \mathrm{P}, \mathrm{RH}$, horizontal winds, precipitation), surface broadband radiative fluxes, surface latent and sensible heat fluxes, soil moisture and temperature, and visible images of the total sky cover.

\subsection{External Datastreams}

There are several different external datastreams that are already archived by the ARM XDC that will be important for accomplishing the scientific objectives of MC3E. These include the surface meteorology network observations from the Oklahoma and Kansas mesonets, the Arkansas River Basin Forecast Center's gridded rainfall product, and model analyses from the European Center for Medium-Range Weather Forecasting (ECMWF) and National Center for Environmental Prediction (NCEP) models.

\subsection{Aircraft and Instrumentation}

NASA will provide two aircraft for MC3E: the NASA ER-2 and University of North Dakota (UND) Citation. These aircraft are being deployed to provide coordinated high-altitude radar and radiometer sampling of precipitation structure and in situ microphysics.

\subsection{NASA ER-2 High-Altitude Aircraft}

The NASA ER-2 will function as a GPM instrument and core-satellite sampling simulator from high altitude during MC3E. The aircraft will operate at a nominal altitude of $20 \mathrm{~km} \mathrm{MSL}$ and will be outfitted with a dual-frequency, dual-beam, nadir-pointing Ka-Ku band Doppler radar (the High Altitude Imaging wind and Rain Airborne Profiler, HIWRAP; Heymsfield et al. 2008), two multi-frequency passive microwave radiometers (the airborne Conical Scanning Millimeter-wave Imaging Radiometer, CoSMIR; and the Advanced Microwave Precipitation Radiometer, AMPR), and a W-band cloud radar (ER-2 Cloud Radar System; CRS). The data collection method for the ER-2 also involves coordinated over-flights of an in situ microphysics aircraft (e.g., UND Citation) located at altitudes below $\sim 10 \mathrm{~km} \mathrm{MSL}$. In this configuration the combined ER-2 and microphysics data collection can be used to validate dual-frequency precipitation and path-integrated attenuation algorithms and combined radar-radiometer precipitation retrieval algorithm physics. 
As mentioned above, the ER-2 will carry the HIWRAP radar, a dual-radiometer (AMPR, CoSMIR) suite, and the CRS cloud-radar (Table 6). The HIWRAP radar is a dual-frequency (Ka- and Ku-band), dualbeam $\left(30^{\circ}\right.$ and $40^{\circ}$ incidence angle), conical scanning, and solid-state transmitter-based system designed for operation on high-altitude $(20 \mathrm{~km})$ aircraft. The AMPR and CoSMIR radiometers will span multiple GMI frequencies from 10 to $183 \mathrm{GHz}$ (Table 6). For MC3E the HIWRAP will be configured primarily to function as a nadir-staring instrument per request of DPR algorithm developers. The CoSMIR radiometer can perform conical and cross-track scanning nearly simultaneously, and the AMPR is a cross-track scanning radiometer. The full scanning capability (which will include a nadir sampling) of the CoSMIR and AMPR radiometers will be employed for MC3E in order to more fully investigate the utility of dualpolarimetric scattering properties of precipitation (in particular the ice phase) in retrieval algorithms. Both radiometers are to be upgraded to full dual-polarization capability prior to the MC3E campaign. The CRS is a dual-polarized nadir-viewing W-band Doppler cloud-radar.

Table 6. ER-2 Radiometer and Radar complement.

\begin{tabular}{|c|c|}
\hline \multicolumn{2}{|c|}{ AMPR (Passive) $\mathrm{H}+\mathrm{V}$ polarizations } \\
\hline Frequencies & $10.7,19.35,37.1,85.5 \mathrm{GHz}$ \\
\hline Resolution at $20 \mathrm{~km}$ range & $\begin{array}{l}0.6 \mathrm{~km}(85.5 \mathrm{GHz}), 1.5 \mathrm{~km}(37.1 \mathrm{GHz}), 2.8 \mathrm{~km} \\
(10.7-19.35 \mathrm{GHz}) \text { in along and cross-track } \\
\text { directions; channels oversampled to produce } \\
0.6 \mathrm{~km} \text { footprint at nadir. }\end{array}$ \\
\hline \multicolumn{2}{|l|}{ CoSMIR (Passive) $\mathrm{H}+\mathrm{V}$ polarizations } \\
\hline Frequencies & $\begin{array}{l}37,89,165.5,183.3+/-1,183.3+/-3,183.3+/-8 \\
\mathrm{GHz}\end{array}$ \\
\hline Resolution at $20 \mathrm{~km}$ range & $1.4 \mathrm{~km}$ footprint at nadir \\
\hline \multicolumn{2}{|l|}{ HIWRAP (Active) } \\
\hline Frequency (inner/outer beam) & 13.91/13.35 GHz, 35.56/33.72 GHz \\
\hline Transmit peak power & $30 \mathrm{~W}(\mathrm{Ku}), 10 \mathrm{~W}(\mathrm{Ka})$ \\
\hline $3 \mathrm{~dB}$ beam width & $2.9^{\circ} \mathrm{Ku}, 1.2^{\circ} \mathrm{Ka}$ \\
\hline $\begin{array}{l}\text { MDS (dBZ }, 60 \mathrm{~m} \text { res., } 3.3 \mu \mathrm{s} \text { chirp pulse, } \\
10 \mathrm{~km} \text { range) }\end{array}$ & $0.0,-5.0 \mathrm{dBZ}_{\mathrm{e}}$ \\
\hline Dynamic range & $65 \mathrm{~dB}$ \\
\hline Beam rotation rate & 10-30 rpm \\
\hline \multicolumn{2}{|l|}{ CRS (Active) } \\
\hline Frequency & $94.15 \mathrm{GHz}$ (dual-polarized) \\
\hline Transmit peak power & $1700 \mathrm{~W}$ \\
\hline $3 \mathrm{~dB}$ beam width & $0.6^{\circ} \times 0.8^{\circ}$ \\
\hline MDS $\left(\mathrm{dBZ}_{\mathrm{e}}, 0.5 \mu \mathrm{s}\right.$ pulse; $1 \mathrm{~km}$ range $)$ & $-35 d B Z_{e}$ \\
\hline Dynamic range & $80 \mathrm{~dB}$ \\
\hline
\end{tabular}

\subsection{University of North Dakota Citation}

The UND Citation will serve as the in situ microphysics sampling platform with a primary emphasis placed on the ice phase at altitudes between the melting level and cloud top altitudes well suited to its operating ceiling of $\sim 12 \mathrm{~km}$. The Citation data will serve as a reference microphysics data set for assessing the scattering properties of ice viewed within the swath of both the ER-2 radiometer and radar 
swaths. As such, microphysical data collections will be conducted in close coordination with the NASA ER-2 high altitude aircraft carrying nadir-viewing radar and radiometer instrumentation.

The citation will carry a standard suite of meteorological instruments ( $\mathrm{T}, \mathrm{P}$, humidity) together with microphysical instrumentation consisting of $1 \mathrm{D}$ and 2D PMS (C, P) probes, liquid water content probes (e.g., forward scattering spectrometer probe, King), and ice and condensation nuclei probes. Particle size distributions (PSD) from cloud to precipitation particle sizes will be measured with a 2D-C or an equivalent Droplet Measurement Technologies (DMT) cloud imaging probe or a Stratton Park Engineering Company (SPEC) 2D-S (stereo) probe, a 2D-P or DMT PIP probe, and a SPEC, Inc. highvolume precipitation spectrometer probe. PSDs measured by these probes will cover the particle diameter range from a minimum of about 20 microns (depending on the probe used and the aircraft true airspeed) to $1 \mathrm{~cm}$ and larger. The $2 \mathrm{D}$ probe data will be processed objectively to remove artifacts produced by shattering on the probes' leading edges (the new Korolev probe tips can be used to further mitigate the shattering). The PSD of small particles, those with diameters from 3 to 50 microns, will be measured using a new generation of open path instruments such as a DMT Cloud Droplet Probe (CDP) and a University of Hertfordshire Small Ice Detector (SID) probe. These probes are less susceptible to shattering in this size range. The condensed water content-liquid plus solid-will be measured using probes such as a Counterflow Virtual Impactor (CVI). For example, DMT manufactures a combined small particle and CVI probe. Liquid water contents can be measured with a King-type hot wire probe above a threshold value of about $0.05 \mathrm{~g} \mathrm{~m}^{-3}$. Supercooled liquid water will be detected using a Rosemount Icing (RICE) Probe. The RICE probe can confidently detect a liquid water content of only $0.02 \mathrm{~g} \mathrm{~m}^{-3}$ (which will be important for stratiform region microphysics). The difference between the total condensed water content (from the CVI, for example) and the supercooled liquid water content (from the RICE) when present, gives the ice water content. Water vapor can be accurately measured with laser diode hygrometers, evaluated and validated in known regions near water saturation (containing cloud water) and near ice saturation (in decaying anvils, for example).

Vertical motions will be derived from air motion sensing systems on research aircraft.

\subsection{Flight Plans}

Several multiple-aircraft flight plans will be conducted during MC3E with some situational variation to be expected based on evolving PMM needs, sampling requirements, air traffic control, and conditions on site. Flight pattern "archetypes" are shown in Figure 11 a-c and emphasize coordinated stacked sampling in and around mesoscale precipitation systems. Note that in addition to sampling precipitation, the ER-2 will also make occasional samples both ahead of and/or behind convective systems to enable sampling of surface radiative characteristics.

Individual flight legs in the figures represent horizontal distances on the order of 50-100 km with endpoints that will generally be translated with the particular system being sampled (i.e., system relative sampling). The ER-2 will sample at a fixed altitude (nominally $20 \mathrm{~km}$ ). The Citation will strongly focus on vertically stepped sampling to provide profiles of particle characteristics in the ice and mixed-phase (e.g., melting level) regions of precipitation, to include the liquid base of the melting level for vertical continuity of the melting process. Vertical separation of the Citation flight legs, when desired, will be on the order of $1 \mathrm{~km}$ above the melting level and no more than $500 \mathrm{~m}$ within and just below the melting level. It is recognized from the outset that the Citation will not be able to penetrate the deepest cores of 
convection associated with spring-time storms in Oklahoma, and thus the patterns emphasize sampling in weaker embedded convection (coalescence processes and cloud water) and broad stratiform precipitation. These patterns will also be coordinated with ground-based sampling to emphasize along radar-beam data collections for testing of range dependencies in GV retrieval algorithms and the impact of these dependencies on validation of the airborne satellite-proxy retrievals.
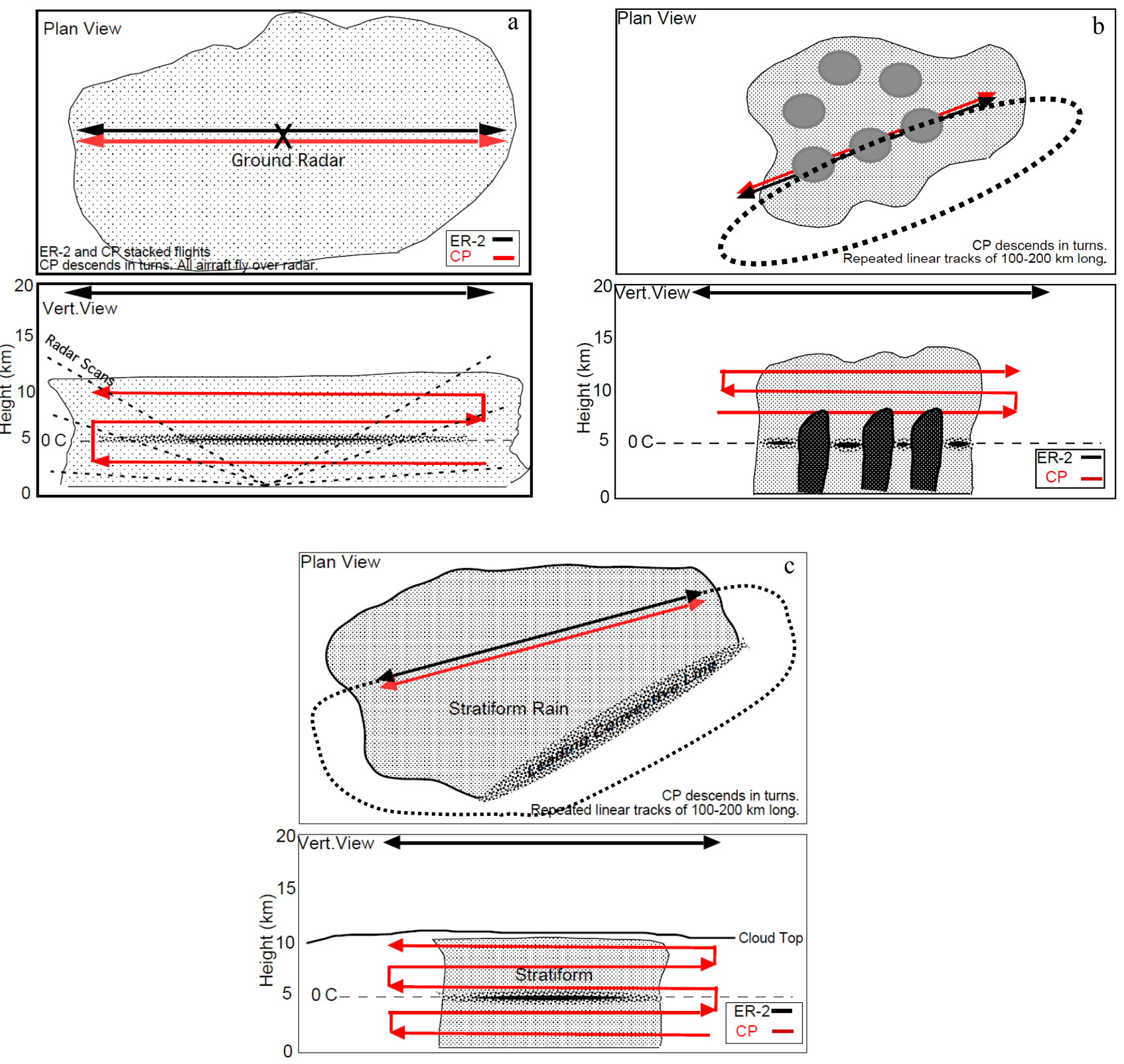

Figure 11. Conceptual diagrams of three flight pattern archetypes to be executed during MC3E:

(a) sampling in MCS stratiform conditions by the ER-2 (black) and Citation (CP; red) along ground-based radar RHI scans; (b) profiling of mixed convective-stratiform conditions; (c) deep sampling of stratiform microphysics and vertical structure of PSD (melting layer included). Solid lines indicate basic patterns while dashed lines indicate occasional sampling of land-surface outside of the precipitation system by ER-2. 
In certain situations (especially those associated with stronger convection). It will be desirable to orient the ER-2 flight legs relative to the convection so that the endpoints extend past the location of deep convection while the Citation leg endpoints remain within the weaker stratiform precipitation. On a target of opportunity basis, it should also be possible to have the Citation fly spiral descents (Lagrangian spirals, if possible) descending from near cloud top through the bright band and into the liquid precipitation below.

Collectively, the flight plans are targeted toward the overarching objectives of:

1. Retrieving collocated dual-frequency radar vertical structure and radiometer brightness temperatures in stratiform and weak convection

2. Profiling of in situ microphysical properties, with particular emphasis placed on the ice phase

3. Verification/calibration of ground-based multi-parameter radar retrievals

4. Selected detailed sampling of the melting layer profiles and microphysics

5. Sampling of pre- and post-storm land surface characteristics at all radar and radiometer frequencies for backscatter cross-section and surface emissivity studies.

\subsection{NWP Support and Forecasting}

The GFS, NAM, and RUC operational models will be used in real time and archived for research purposes through the ARM External Data Center.

Real-time access to numerical weather prediction output (from GFS, NAM, RUC), geostationary satellite observations, and NWS radar systems will provide the tools necessary for accurate forecasts of the 2-3 day convective state. The SGP site scientist office will be supplying experienced forecasting support for the experiment team during the field deployment for choosing convective and non-convective field campaign days.

\subsection{Satellite Data Sets}

Real-time geostationary satellite images will be useful for experimental planning and qualitative descriptions of the large-scale cloud characteristics. Geostationary satellite data products produced by the NASA Langley group, including top-of-atmosphere (TOA) fluxes and cloud properties, will be an important complement to the surface and aircraft-based observations. NASA polar orbiting satellites will also provide important additional information in many cases. Of particular importance will be the TRMM satellite (for convective systems in the southern portion of the sounding array), Terra, Aqua, CloudSat, and CALIPSO satellites. The combination of passive and active satellite observations of any systems in the MC3E domain will be a useful additional constraint for addressing the scientific questions. 


\subsection{References}

Armijo, L. 1969. "A theory for the determination of wind and precipitation velocities with Doppler radars." Journal of Atmospheric Sciences 26: 570-573.

Browning, KA, et al. 2007. "The convective storm initiation project." Bulletin of the American Meteorological Society 88: 1939-1955.

Bryan, GH, JC Wyngaard, and JM Fritsch. 2003. "Resolution requirements for the simulation of deep convection." Monthly Weather Review 131: 2394-2416.

Chen, S-H, and W-Y Sun. 2002. “A one-dimensional time-dependent cloud model." Journal of the Meteorological Society of Japan 80: 99-118.

Cheong, BL, RD Palmer, CD Curtis, T-Y Yu, DS Zrnic, and D Forsyth. 2008. "Refractivity retrieval using the phased-array radar: First results and potential for multimission operation." IEEE Transactions on Geoscience and Remote Sensing 46: 2527-2537.

Ciach, GJ, and WJ Krajewski. 2006. "Analysis and modeling of spatial correlation structure in smallscale rainfall in central Oklahoma." Advances in Water Resources 29: 1450-1463.

Clement, AC, and BJ Soden. 2005. "The sensitivity of the tropical-mean radiation budget." Journal of Climate 18(16): 3189-3203.

Clothiaux, EE, TP Ackerman, GG Mace, KP Moran, RT Marchand, MA Miller, and BE Martner. 2000. "Objective determination of cloud heights and radar reflectivities using a combination of active remote sensors at the ARM CART sites." Journal of Applied Meteorology 39: 645-665.

Crook, NA. 1996. "Sensitivity of moist convection forced by boundary layer processes for low-level thermodynamic fields." Monthly Weather Review 124: 1767-1785.

Dai, A. 2001. "Global precipitation and thunderstorm frequencies. Part II: Diurnal variations.” Journal of Climate 14: 1112-1128.

Dai, A. 2006. "Precipitation characteristics in eighteen coupled climate models." Journal of Climate 19: 4605-4630.

Del Genio, AD, W Kovari, M-S Yao, and J Jonas. 2005. "Cumulus microphysics and climate sensitivity." Journal of Climate 18: 2376-2387.

Del Genio, AS, and J Wu. 2010. "The role of entrainment in the diurnal cycle of continental convection." Journal of Climate, in press, doi:10.1175/2009JCLI3340.1.

Derbyshire, SH, I Beau, P Bechtold, J-Y Grandpiex, JM Pirou, J-L Redelsperger, and PMM Soares. 2004. "Sensitivity of moist convection to environmental humidity." Quarterly Journal of the Royal Meteorological Society 130: 3055-3079. 
Fabry, F. 2004. "Meteorological value of ground target measurements by radar." Journal of Atmospheric and Oceanic Technology 21: 560-573.

Fabry, F, C Frush, I Zawadzki, and A Kilambi. 1997. "Extracting near-surface index of refraction using radar phase measurements from ground targets." Journal of Atmospheric and Oceanic Technology 14: 978-987.

Grabowski, WW. 2001. "Coupling cloud processes with the large-scale dynamics using the CloudResolving Convective Parameterization (CRCP).” Journal of Atmospheric Science 58: 978-997.

Grabowski, WW, and PK Smolarkiewicz. 1999. "CRCP: A cloud resolving convective parameterization for modeling the tropical convective atmosphere." Physica D 133: 171-178.

Grecu, M, WS Olson, and EN Anagnostou. 2004. "Retrieval of precipitation profiles from multiresolution, multifrequency active and passive microwave observations." Journal of Applied Meteorology 43: 562-575.

Guichard, D, et al. 2004. "Modelling the diurnal cycle of deep precipitating convection over land with cloud resolving models and single column models." Quarterly Journal of the Royal Meteorological Society 130: 3139-3172.

Habib, E, and W Krajewski. 2002. "Uncertainty analysis of the TRMM ground-validation radar rainfall products: Application to the TEFLUN-B field campaign." Journal of Applied Meteorology 41: 558-572.

Heymsfield, G, J Carswell, L Li, D Shaubert, and J Crecitos. 2008. "Development of the High-Altitude Imaging Wind and Rain Airborne Profiler." Proceedings of the Eighth Annual NASA Earth Science Technology Conference. College Park, MD.

Hong, S-Y, J Dudhia, and S-H Chen. 2004. "A revised approach to ice microphysical processes for the bulk parameterization of clouds and precipitation." Monthly Weather Review 132: 103-120.

Hou, AY, GS Jackson, CD Kummerow, and JM Shepard. 2008. "Global precipitation measurement." In Precipitation: Advances in Measurement, Estimation and Prediction. Ed. S. Michaelidas, Springer, pp. 131-169.

Iguchi, et al. 2009. "Uncertainties in the rain profiling algorithm for the TRMM precipitation radar." Journal of the Meteorological Society 87A: 1-30.

Jensen, MP, and KL Johnson. 2006. "Continuous profiles of cloud microphysical properties for the fixed Atmospheric Radiation Measurement sites." http://www.arm.gov/publications/programdocs/doe-sc-armp-06-009.pdf.

Joss, J, and A Waldvogel. 1969. "Raindrop size distribution and sampling size errors." Journal of Atmospheric Science 26: 566-569.

Khairoutdinov, MF, and DA Randall. 2001. "A cloud resolving model as a cloud parameterization in the NCAR Community Climate System Model: Preliminary results." Geophysical Research Letters 28: $3617-3620$. 
Khairoutdinov, M, and DA Randall. 2006. "High-resolution simulation of shallow-to-deep convection transition over land." Journal of Atmospheric Science 63: 3421-3436.

Klein SA, and AD Del Genio. 2006. ARM's Support for GCM Improvement: A White Paper. U.S. Department of Energy. DOE/SC-ARM/P-06-012.

Kollias, P, EE Clothiaux, MA Miller, EP Luke, KL Johnson, KP Moran, KB Widener, and BA Albrecht. 2007. "The atmospheric radiation measurement program cloud profiling radars: second-generation sampling strategies, processing, and cloud data products." Journal of Atmospheric Science 24: doi:10.1175/JTECH2033.1.

Kuang, Z, and CS Bretherton. 2006. "A mass-flux scheme view of a high-resolution simulation of a transition from shallow to deep cumulus convection." Journal of Atmospheric Science 63: 1895-1909.

Lang, TJ, DA Ahijevych, SW Nesbitt, RE Carbone, SA Rutledge and R. Cifelli. 2007. "Radar-observed characteristics of precipitating systems during NAME 2004.” Journal of Climate 20: 1693-1712.

Lee, G-W, and I Zawadski. 2005. "Variability of drop size distributions: Time-scale dependence of the variability and its effects on rain estimation." Journal of the Meteorological Society 44: 241-255.

Lim, S, V Chandrasekar, and VN Bringi. 2005. "Hydrometeor classification system using dualpolarization radar measurements: Model improvements and in situ verification." IEEE Transactions of Geoscience and Remote Sensing 43: 792-801.

Liu, H, and V Chandrasekar. 2000. "Classification of hydrometeors based on polarimetric radar measurements: Developments of fuzzy logic and neuro-fuzzy systems, and in situ verification." Journal of Atmospheric and Oceanic Technology 17: 140-164.

Lucas, C, MA LeMone, and EJ Zipser. 1994. "Vertical velocity in oceanic convection off tropical Australia." Journal of Atmospheric Sciences 57: 3183-3193.

Luke, EP, P Kollias, KL Johnson, and EE Clothiaux. 2008. "A technique for the automatic detection and removal of insect clutter in cloud radar returns." Journal of Atmospheric and Oceanic Technology 25: 1498-1513, doi:10.1175/2007JTECHA953.1.

Matejka, T, and DL Bartels. 1998. "The accuracy of vertical air velocities from Doppler radar data." Monthly Weather Review 126: 92-117.

May, PT, and TD Keenan. 2005. "Evaluation of microphysical retrievals from polarimetric radar with wind profiler data." Journal of Applied Meteorology 44: 827-838.

McPherson, RA, CA Fiebrich, KC Crawford, JR Kilby, DL Grimsley, JE Martinez, JB Basara, BG Illston, DA Morris, KA Kloesel, AD Melvin, and H Shrivastava. 2007. "Statewide monitoring of the mesoscale environment: A technical update on the Oklahoma Mesonet." Journal of Atmospheric and Oceanic Technology 24: 301-321.

Miriovsky, BJ, et al. 2004. "An experimental study of small-scale variability of radar reflectivity using disdrometer observations." Journal of Applied Meteorology 43: 106-118. 
Moran, KP, BE Martner, MJ Post, RA Kropfli, DC Welsh, and KB Widener. 1998. "An unattended cloud-profiling radar for use in climate research." Bulletin of the American Meteorological Society 79: $443-455$

O'Brien, JJ. 1970. "Alternative solutions to the classical vertical velocity problem." Journal of Applied Meteorology 9: 197-203.

Ovtchinnokov, M, TP Ackerman, RT Marchand, and M Khairoutdinov. 2006. "Evaluation of the multiscale modeling framework using data from the Atmospheric Radiation Measurement program." Journal of Climate 19: 1716-1729.

Park, H, AV Ryzhkov, DS Zrnic, and K-E Kim. 2008. "The hydrometeor classification algorithm for the polarimetric WSR-88D: Description and application to an MCS." Weather and Forecasting, in press, doi:10.1175/2008WAF2222205.1.

Protat, A, and I Zawadki. 2000. "Optimization of dynamic retrievals from a multiple-Doppler radar network." Journal of Atmospheric and Oceanic Technology 17: 753-760.

Ramachandran, R, AG Detweiler, JH Helsdon Jr., PL Smith, and VN Bringi. 1996. "Precipitation development and electrification in Florida thunderstorm cells during CaPE." Journal of Geophysical Research 101: 29,615-29,626.

Randall, DA, M Khairoutdinov, A Arakawa, and W Grabowski. 2003: "Breaking the cloudparameterization deadlock." Bulletin of the American Meteorological Society 84: 1547-1564.

Ray, PS, RJ Doviak, GB Walker, D Sirmans, J Carter, and B Bumgarner. 1975. "Dual-Doppler observations of a tornadic storm." Journal of Applied Meteorology 14: 1521-1530.

Ray, PS, CL Ziegler, W Bumgarner, and RJ Serafin. 1980. "Single- and multiple-Doppler radar observations of tornadic storms." Monthly Weather Review 108: 1607-1625.

Richardson, YP, JM Wurman, and C Hartman. 2003. "Multi-doppler analysis of convective initiation on 19 June 2002." Preprints, American Meteorology Society's $31^{\text {st }}$ Conference on Radar Meteorology, 6-12 August, 2003, Seattle, WA.

Roberts, RD, F Fabry, PC Kennedy, E Nelson, JW Wilson, N Rehak, J Fritz, V Chandrasekar, J Braun, J Sun, S Ellis, S Reising, T Crum, L Mooney, R Palmer, T Weckworth, and S Padmanabhan. 2008. "REFRACTT 2006: Real-time retrieval of high resolution, low-level moisture fields from operational NEXRAD and research radars." Bulletin of the American Meteorological Society 89: 1535-1548.

Shapiro, A, and JJ Mewes. 1999. "New formulations of dual-Doppler wind analysis." Journal of Atmospheric and Oceanic Technology 16: 782-792.

Silva Dias, MAF, and Co-authors. 2002. "Cloud and rain processes in biosphere-atmosphere interaction context in the Amazon region." Journal of Geophysical Research 107: doi:10.1029/2001JD000335.

Skamarock, WC, JB Klemp, J Dudhia, DO Gill, DM Barker, W Wang, and JG Powers. 2007. A description of the advanced research WRF version 2. NCAR. NCAR/TN-468+STR. 
Stonitsch J, and P Markowski. 2005. "Evolution of boundary layer wind and moisture fields along a front during IHOP." Proceedings of the $31^{\text {st }}$ American Meteorological Society Conference on Radar Meteorology, Albuquerque, NM.

Testud, J, and M Chong. 1983. "Three-dimensional wind field analysis from dual-Doppler radar data. Part I: Filtering, interpolation and differentiating the raw data." Journal of Climate and Applied Meteorology 22: 1204-1215.

Thompson, G, RM Rasmussen, and K Manning. 2004. "Explicit forecasts of winter precipitation using an improved bulk microphyiscs scheme. Part I: Description and sensitivity analysis." Monthly Weather Review 132: 519-542.

Vivekananadan, J, DS Zrnic, SM Ellis, R Oye, AV Ryzhkov, and J Straka. 1999. "Cloud microphysics retrieval using S-band dual-polarization radar measurements." Bulletin of the American Meteorological Society 80: 381-388.

Williams, CR, AB White, KS Gage, and FM Ralph. 2007. "Vertical Structure of Precipitation and Related Microphysics Observed by NOAA Profilers and TRMM during NAME 2004." Journal of Climate 20: 1693-1712.

Wu, J, AD Del Genio, M-S Yao, and AB Wolf. 2009. "WRF and GISS SCM simulations of convective updraft properties during TWP-ICE.” Journal of Geophysical Research 114: D04206, doi:10.1029/2008JD010851.

Wu, X, L Deng, X Song, G Vettoretti, WR Peltier, and GJ Zhang. 2007. "Impact of a modified convective scheme on the MJO and ENSO in a coupled climate model." Geophysical Research Letters 34, L16823, doi:10.1029/2007GL030637.

Yuter, SE, and RA Houze, Jr. 1995a. "Three-dimensional kinematic and microphysical evolution of Florida cumulonimbus. Part I: Spatial distribution of updrafts, downdrafts, and precipitation." Monthly Weather Review 123: 1921-1940.

Yuter, SE, and RA Houze, Jr. 1995b. "Three-dimensional kinematic and microphysical evolution of Florida cumulonimbus. Part II: Frequency distributions of vertical velocity, reflectivity and differential reflectivity." Monthly Weather Review 123: 1941-1963.

Zhang, MH, and JL Lin. 1997. "Constrained variational analysis of sounding data based on columnintegrated budgets of mass, heat, moisture and momentum: approach and application to ARM measurements." Journal of Atmospheric Science 54: 1503-1524.

Zipser, EJ, and K Lutz. 1994. "The vertical profile of radar reflectivity of convective cells: A strong indicator of storm intensity and lightning probability." Monthly Weather Review 122: 1751-1759.

Zrnic, DS, and A Ryzhkov. 1999. "Polarimetry for weather surveillance radars." Bulletin of the American Meteorological Society 80: 389-406.

Zrnic, DS, A Ryzhkov, J Straka, Y Liu, and J. Vivekanandan. 2001. "Testing a procedure for automatic classification of hydrometeor types." Journal of Atmospheric and Oceanic Technology 18: 892-913. 


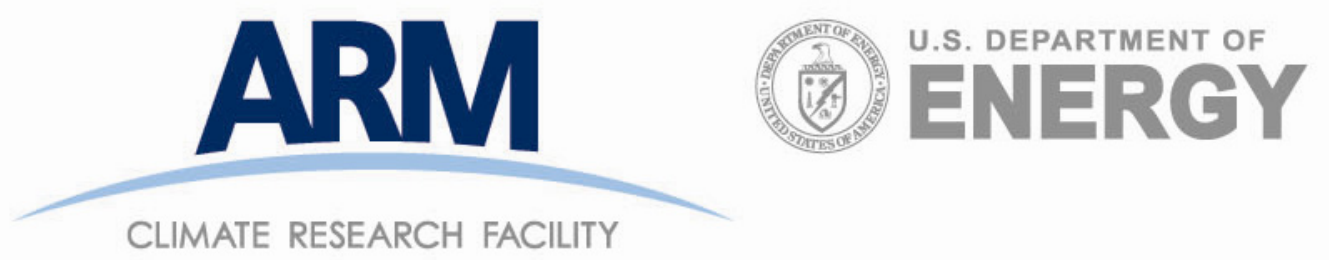

wWw.arm.gov 